\title{
Monitoring Suaeda salsa Spectral Response to Salt Conditions in Coastal Wetlands: A Case Study in Dafeng Elk National Nature Reserve, China
}

\author{
Xia Lu ${ }^{1,2}$, Sen Zhang ${ }^{1,2}$, Yanqin Tian ${ }^{1,2}$, Yurong $\mathrm{Li}^{1,2}$, Rui Wen ${ }^{3}$, Jin Yau Tsou ${ }^{4,5}$ and \\ Yuanzhi Zhang 5,6,* \\ 1 Jiangsu Key laboratory of Marine Bioresources and Environment/Jiangsu Key laboratory of Marine \\ Biotechnology/Co-Innovation Center of Jiangsu Marine Bio-Industry Technology, Jiangsu Ocean University, \\ Lianyungang 222005, China; 2008000070@jou.edu.cn (X.L.); Zhangsen.henan@jou.edu.cn (S.Z.); \\ tianyq@jou.edu.cn (Y.T.); liyurong2018@jou.edu.cn (Y.L.) \\ 2 School of Geomatics and Marine Information, Jiangsu Ocean University, Lianyungang 222005, China \\ 3 Third Institute of Oceanography, Ministry of Natural Resources, Xiamen 361005, China; wenrui@tio.org.cn \\ 4 Department of Architecture and Civil Engineering, City University of Hong Kong, Hong Kong, China; \\ jinyeutsou@cuhk.edu.hk \\ 5 Faculty of Social Science and Asia-Pacific Studies Institute, Chinese University of Hong Kong, \\ Hong Kong, China \\ 6 School of Marine Science, Nanjing University of Information Science and Technology, Nanjing 210044, China \\ * Correspondence: yuanzhizhang@cuhk.edu.hk; Tel.: +86-188-8885-3470
}

Received: 17 July 2020; Accepted: 17 August 2020; Published: 20 August 2020

\begin{abstract}
This paper reports on monitored Suaeda salsa spectral response to salt conditions in coastal wetlands, using spectral measurements and remotely sensed algorithms. Suaeda salsa seedlings were collected from the Dafeng Elk National Nature Reserve (DENNR) in Jiangsu Province, China. We treated 21 Suaeda salsa seedlings planted in pots with 7 different salt concentrations ( $\mathrm{n}=3$ for each concentration) to assess their response to varying salt conditions. Various plant growth indicators, including chlorophyll content, fresh weight, dry weight, and canopy hyperspectral reflectance, were measured. One-way analysis of variance (ANOVA) and post hoc multiple comparisons of least-significant difference (LSD) were used to explore the physiological indicators of sensitivity to salt treatment. Red edge parameters and spectral reflectance indices were used to analyze spectral response to salt conditions and to investigate the potential for remotely sensing physiological parameters which are sensitive to salt conditions. The results indicated that among these physiological indicators, the total chlorophyll content differed significantly with salt conditions, being highest at $50 \mathrm{mmol} / \mathrm{L}$, whereas the differences observed for the morphological parameters were highest at $200 \mathrm{mmol} / \mathrm{L}$. In addition, new vegetation indices were significantly more responsive to salt concentrations than were traditional red edge parameters. The two vegetation indices, $D_{854} / D_{792}$ and $\left(D_{792}-D_{854}\right) /\left(D_{792}\right.$ $+\mathrm{D}_{854}$ ), were the most sensitive to the total chlorophyll content, and these also strongly correlated with salt concentrations. An analysis of the responses of plant growth indicators to salt treatment showed that soil having a salt concentration of $50 \sim 200 \mathrm{mmol} / \mathrm{L}$ is most suitable for the growth of Suaeda salsa. These results suggest the potential for using remote sensing to effectively interpret the causes of salt-induced spectral changes in Suaeda salsa. This methodology also provides a new reference for the inversion model of estimating the total chlorophyll content of Suaeda salsa under different salt concentrations in similar coastal wetlands, whether in China or elsewhere.
\end{abstract}

Keywords: coastal wetlands; Suaeda salsa; salt conditions; reflectance spectra; spectral response 


\section{Introduction}

Coastal wetlands, which are among the most important ecosystems in the world, are important for the economic and social development of coastal areas, playing a significant role in the development of offshore fisheries and the protection of endangered species [1]. However, the overexploitation of coastal biotic resources for the purposes of economic development has degraded the ecological environment of coastal wetlands, endangering vegetation and wildlife habitats [2,3]. Because soil salinization has played a notable role in degrading coastal wetlands [4], the planting of halophyte vegetation [2] has been considered as a way of achieving ecological restoration of coastal wetlands. As an important salt-tolerant plant in coastal wetlands, Suaeda salsa has great potential for the ecological restoration of wetlands [5]. Not only can it absorb large amounts of soil salt for storage in its thick leaves, but it can also accumulate and absorb heavy metals from the soil, improving and restoring damaged coastal wetland ecosystems [6-8]. Furthermore, it can adapt to different water and salt environments in the intertidal and upper tidal zones by adjusting its morphological characteristics and biomass allocation, thus maintaining population stability and improving salinized soil [9].

Soil moisture and salinity are the two most important factors affecting halophyte growth [10-12]; therefore, some researchers have focused on the relationship between the growth and population distribution of Suaeda salsa and salt stress and chemical elements in the soil [13-18]. Salt-induced vegetation growth and physiology response, such as changes in biomass and chlorophyll content, usually lead to corresponding changes in canopy reflectance spectra. To monitor the response of Suaeda salsa to salt stress using information provided by remote sensors, further exploration of the response mechanism is needed, using detailed spectral signals [10].

Hyperspectral sensors can detect signals of hundreds of continuous spectral bands with a spectral interval of $<10 \mathrm{~nm}$ within the visible and near-infrared spectrum [19,20]. By collecting information on plant spectra that are affected by biotic and abiotic stress, hyperspectral sensors become a powerful tool for quantitative vegetation monitoring [18]. Various studies have investigated the use of hyperspectral remote sensing techniques to classify halophyte plants [21], examine the responses of hyperspectral indices to soil chemical properties [22], analyze the spectral characteristics of halophyte plants [23], and estimate the Suaeda salsa biomass [24,25]. The red edge, as one of the most prominent features in the vegetation spectrum, is often used to detect various physical parameters of vegetation [26-28]. For example, red edge position can be used to estimate the leaf area index (LAI) and chlorophyll content of vegetation [29]; red edge area can be used to estimate the chlorophyll density of vegetation [30]; red edge amplitude can be used to estimate the biomass and relative water content of vegetation [31]; and red edge skewness and kurtosis are used to estimate chlorophyll content [32]. The high absorption of vegetation chlorophyll in the red light band, and the multiple reflections of the near-infrared band inside the vegetation leaves, form a strong reflection and, eventually, a unique "steep slope" phenomenon in the $680-750 \mathrm{~nm}$ region. In addition, vegetation indices are another method that is often used in the remote sensing of vegetation. This approach mainly uses specific bands for combined operations to improve correlation with the physiological parameters of vegetation. This method is widely applied in the dynamic monitoring of vegetation [33,34] and biophysical inversion. However, comparisons of these methods applied to Suaeda salsa communities have seldom been reported.

Taking a new approach, i.e., combining spectral characteristics with plant growth indicators under various salt conditions, this study investigates the response of salt stress to the growth indicators and hyperspectral reflectance spectra of Suaeda salsa. Its objectives are (1) to study changes in growth indicators of Suaeda salsa which are susceptible to salt treatment, (2) to monitor red edge parameters and the response of vegetation indices, and (3) to provide a reference for estimating the physiological parameters of Suaeda salsa under various salt conditions in degraded coastal wetlands. 


\section{Materials and Methods}

\subsection{Materials}

Suaeda salsa seedlings were collected in the third core zone of the Dafeng Elk National Nature Reservation $\left(120^{\circ} 47^{\prime}-120^{\circ} 53^{\prime}\right.$ E, $\left.32^{\circ} 59^{\prime}-33^{\circ} 03^{\prime} \mathrm{N}\right)$ in Jiangsu Province, China (Figure 1), the largest elk nature reserve in the world. The study area is in the transition zone between the subtropics and a warm temperate zone, with relatively high humidity. Mean precipitation is $1068 \mathrm{~mm} /$ year, and the average annual temperature is $14.1^{\circ} \mathrm{C}$. The soil is mainly coastal saline soil in meadows and tidal beaches. The dominant plant species are Spartina alterniflora, Suaeda salsa, Zoysia macrostachya, Phragmites australis, and Imperata cylindrica. The national reserve's total area is about $780 \mathrm{~km}^{2}$, divided into a core zone, a buffer zone, and an experimental zone. The core zone is subdivided into three further zones: in the first and second, elk are kept in captivity, but in the third, they live in a "wild pastoral area" [35].
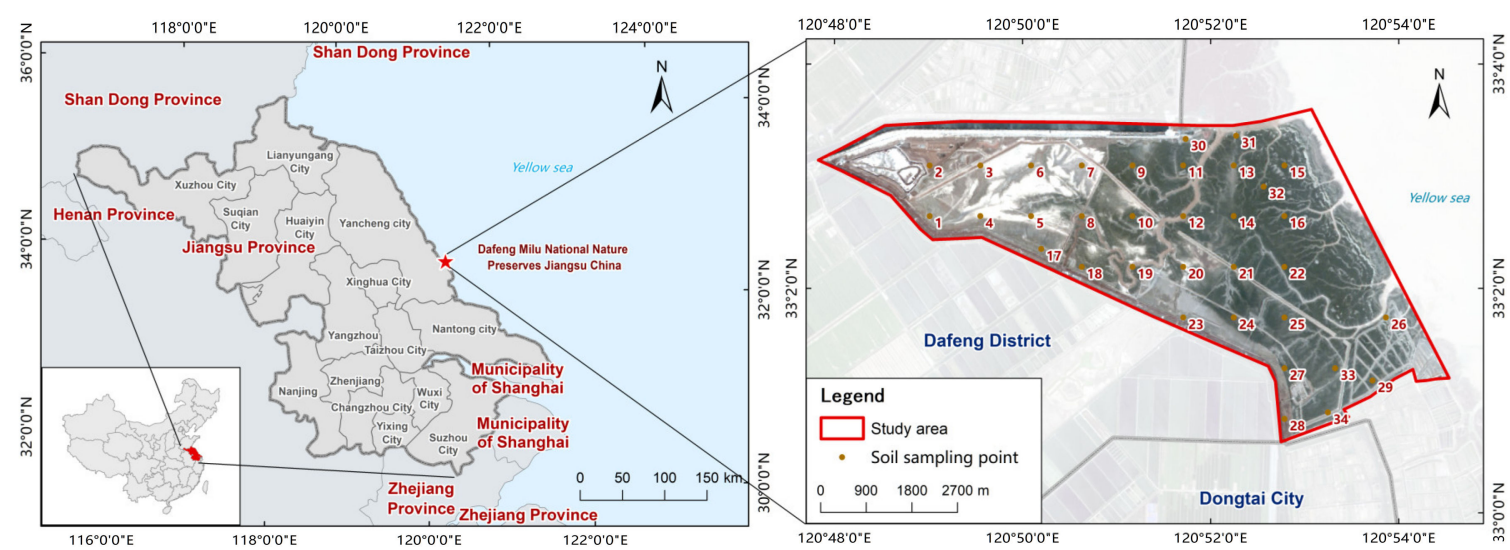

Figure 1. The study area at the Dafeng Elk National Nature Reserve in China.

\subsection{Experimental Design}

\subsubsection{Field Survey}

Plant communities of Suaeda salsa and their habitat soil surveys were studied at the coastal saltmash in Dafeng City, Jiangsu Province, China, which previous studies have identified as having medium and heavily saline soil. A total of 34 topsoil samples (0-20 cm depth) from each $1000 \mathrm{~m}$ by $1000 \mathrm{~m}$ quadrant were taken in April 2016 (see Figure 1). An extract solution (gravimetric soil:water = 1:5) of a soil sample was used to measure soil EC and pH with a conductivity meter (Horiba, B-173, Tokyo, Japan) and digital pH meter (HI98121). The total soil salt content (SSC) was calculated based on the linear relationship between the conductivity and salinity of the standard KCL solution. The Kjeldahl method was used to determine the total nitrogen content (TN), the soil organic matter (SOM) content was determined by hydration thermal potassium dichromate oxidation-colorimetry, the nitrate nitrogen (NN) content was determined by ultraviolet spectrophotometry, the total carbon (TC) content was determined by the wet burning method, the content of available potassium (AK) was measured by the turbidimetric method of sodium tetraphenylborate, and the content of available phosphorus (AP) was measured using an ultraviolet/visible spectrophotometer.

\subsubsection{Pot Experiment Design}

Suaeda salsa seedlings of similar heights $(13-15 \mathrm{~cm} \pm 0.5 \mathrm{~cm}$ for plant height, $5-8 \mathrm{~cm} \pm 0.5 \mathrm{~cm}$ for root length) were collected from the same experimental site $(100 \mathrm{~m} \times 100 \mathrm{~m})$. Twenty-one pots were divided into seven groups by salt gradient treatment, with each set containing three replicates (Figure 2). Before planting, we used deionized water to wash the roots of each specimen, and then transplanted them into 21 pots $(18.5 \mathrm{~cm}$ in diameter, $24.5 \mathrm{~cm}$ in height), using 20-40 mesh dry sand 
as the medium. Each plastic basin had a $1.5 \mathrm{~cm}$ vent hole that we covered with a layer of gauze to prevent the internal sand from flowing out during irrigation.
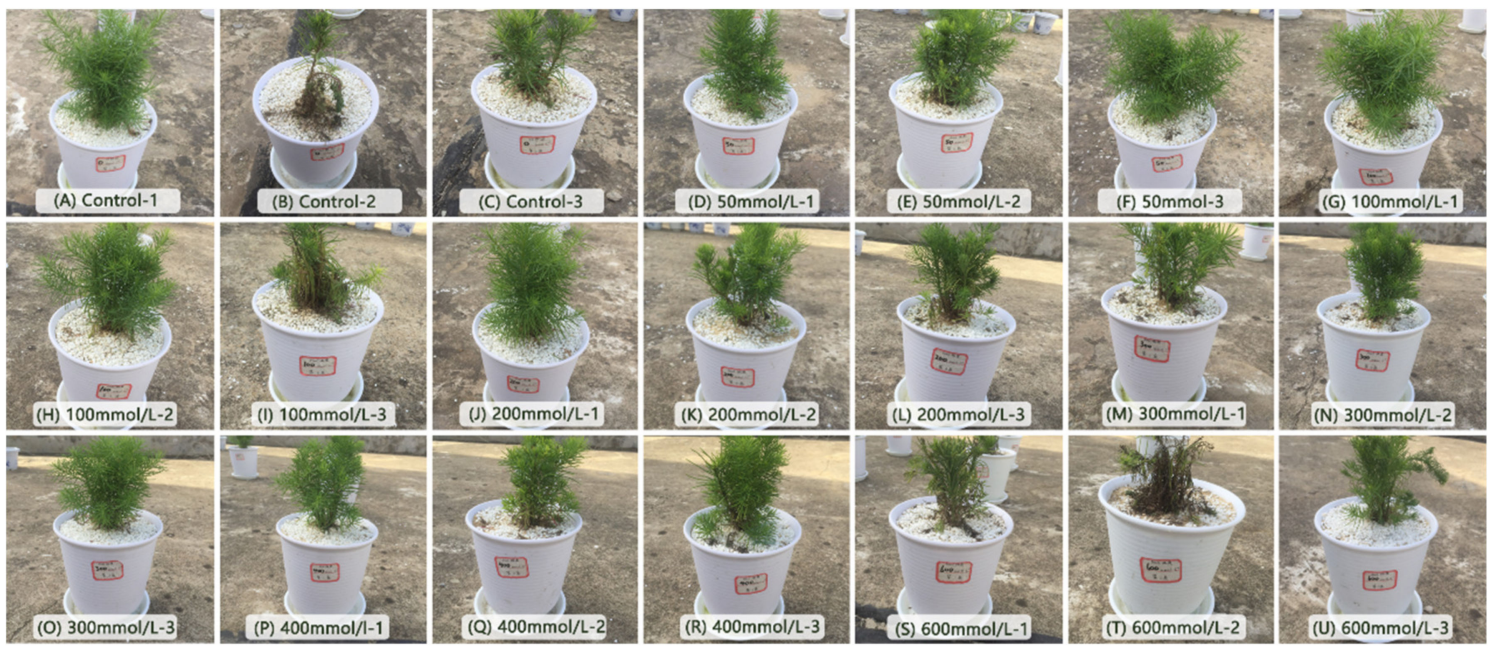

Figure 2. Photographs of potted plants of Suaeda salsa under salt stress in seven groups (taken on the last day of the experiment). Each group of experiments consisted of three pots of samples, in which photos $(\mathbf{A}-\mathbf{C})$ are the Control group, $(\mathbf{D}-\mathbf{F})$ are the V-L group, $(\mathbf{G}-\mathbf{I})$ are the L group, and $(\mathbf{J}-\mathbf{L})$ are the M group, $(\mathbf{M}-\mathbf{O})$ are the $\mathrm{H}$ group, $(\mathbf{P}-\mathbf{R})$ are the $\mathrm{V}-\mathrm{H}$ group, and $(\mathbf{S}-\mathbf{U})$ are the $\mathrm{E}-\mathrm{H}$ group.

Before salt treatment, it took a week to restore Suaeda salsa to growth. During this period, 21 pots were irrigated with pure water every morning and evening. The amount of irrigation was twice the amount of dry sand in the pot, and it flowed out of the cavity to ensure that the small amount of salt contained in the dry sand was washed away. We started watering the Suaeda salsa seedlings with seven different levels of salt in Hogland's nutrient solution $(\mathrm{PH}=6.7 \sim 7.0)$ every morning and evening. Salt concentrations were $25 \mathrm{mmol} / \mathrm{L}$ (the control), $50 \mathrm{mmol} / \mathrm{L}, 100 \mathrm{mmol} / \mathrm{L}, 200 \mathrm{mmol} / \mathrm{L}$, $300 \mathrm{mmol} / \mathrm{L}, 400 \mathrm{mmol} / \mathrm{L}$, and $600 \mathrm{mmol} / \mathrm{L}$, and irrigation amounts were twice the water content in the pot. Each treatment was conducted under the same conditions of natural light, atmospheric environment, temperature, and humidity. The control group was irrigated with $25 \mathrm{mmol} / \mathrm{L}$, i.e., an extremely low salt concentration, close to that of the natural salt environment. By the 15th day of the experiment, the plants treated with the $600 \mathrm{mmol} / \mathrm{L}$ salt solution had begun to wither and were near death, so we concluded the experiment.

For the sake of simplicity, the treatment names will be simplified for the rest of the manuscript: control ( $25 \mathrm{mmol} / \mathrm{L}$ extremely low (E-L) salinity), $50 \mathrm{mmol} / \mathrm{L}$ very low (V-L) salinity, $100 \mathrm{mmol} / \mathrm{L}$ low (L) salinity, and $200 \mathrm{mmol} / \mathrm{L}$ medium (M) salinity, $300 \mathrm{mmol} / \mathrm{L}$ high (H) salinity, $400 \mathrm{mmol} / \mathrm{L}$ very high (V-H) salinity, and $600 \mathrm{mmol} / \mathrm{L}$ extremely high (E-H) salinity [36].

\subsection{Plant Growth Indicators}

The day before the end of the experiment, we measured plant height and the number of branches. After ending the experiment, we removed the harvested plants and washed away the sand and dust using distilled water, dried the plants using absorbent paper, and determined the fresh weight (FW) above ground and FW in the roots for each. We oven-dried the plant samples at $105{ }^{\circ} \mathrm{C}$ for $10 \mathrm{~min}$, and then at $80^{\circ} \mathrm{C}$ until a constant weight was achieved. Next, we measured the dry weight (DW). Based on FW and DW, we computed the degree of leaf succulence as FW:DW.

We collected and crushed about $0.5 \mathrm{~g}$ of fresh leaf of Suaeda salsa from each plant, and then extracted the chlorophyll content with $90 \%$ acetone for $24 \mathrm{~h}$, using three plants for each salinity level. We used a spectrophotometer (Hitachi U-2001, Hitachi Ltd., Tokyo, Japan) to measure the absorbency of the extraction solution at $665 \mathrm{~nm}, 649 \mathrm{~nm}$, and $470 \mathrm{~nm}$. We then calculated the chlorophyll a content 
(chl-a), chlorophyll b content (chl-b), total chlorophyll content $\left(c h l_{T}\right)$, and carotenoid content $\left(C_{k}\right)$ using Equations (1)-(4) [37]:

$$
\begin{gathered}
c h l-a=13.95 A_{665}-6.88 A_{649} \\
c h l-b=24.96 A_{649}-7.32 A_{665} \\
C_{k}=\left(1000 A_{470}-2.05 c h l-a-114.8 c h l-b\right) / 245 \\
C h l_{T}=c h l-a+c h l-b=18.08 A_{649}+6.63 A_{665}
\end{gathered}
$$

where chl-a and chl-b are chlorophyll $a$ and $b$ content, respectively; $C_{k}$ is carotenoid content; $C h l_{T}$ is total chlorophyll content; and $A$ is the absorbency of the extraction solution.

\subsection{Hyperspectral Measurement and Pre-Processing}

On the last day of the experiment, we measured the canopy hyperspectral reflectance spectra of Suaeda salsa. We made all canopy reflectance measurements using an SVC (Spectra Vista Corporation) HR-1024i field-portable spectroradiometer (SVC Inc., San Jose, CA, USA) that covered ultraviolet, visible, and near-infrared wavelengths from $350 \mathrm{~nm}$ to $2500 \mathrm{~nm}$. Hyperspectral resolution was less than $3.5 \mathrm{~nm}, 9.5 \mathrm{~nm}$, and $6.5 \mathrm{~nm}$ in the ranges $350-1000 \mathrm{~nm}, 1000-1850 \mathrm{~nm}$, and $1850-2500 \mathrm{~nm}$, respectively. We measured canopy reflectance spectra from $40 \mathrm{~cm}$ above the canopy using $25^{\circ}$ field-of-view fiber optics between 10 a.m. and 2 p.m. (Beijing time) on a sunny day. The spectral measurement scan time for each pot was $5 \mathrm{~s}$, with the average reflectance spectra of 10 measurements being taken as the final spectrum of each pot.

The hyperspectral reflectance spectra of Suaeda salsa at the canopy level were preprocessed by the following steps. First, the abnormal high and low hyperspectral reflectance due to light or wind conditions were identified and deleted. Second, the spectral data were resampled. Finally, the various sets of spectral data were merged using the SVC HR-1024i software. The 350 to $499 \mathrm{~nm}$ noise bands were removed from the spectral curve of each sample, and the 500-900 nm bands were selected. A Savitzky-Golay (S-G) smoothing filter was applied to smooth the reflectance data to reduce the instrument and environment noise for the further quantitative analysis.

\subsection{Data Analysis}

\subsubsection{Calculation of Red Edge Parameters}

First derivatives were calculated based on the preprocessed hyperspectral reflectance spectra, and were employed to obtain five red edge parameters between 680 and $750 \mathrm{~nm}$, i.e., red edge area, red edge amplitude, red edge skew coefficient, red edge kurtosis coefficient, and red edge position (see Table 1).

Table 1. Definition and algorithm of red edge parameters.

\begin{tabular}{ccc}
\hline Red Edge Parameter & Definition & Algorithm \\
\hline Red edge area [38] & The area of first derivative in the red edge & $(680 \sim 750 \mathrm{~nm})$ \\
Red edge amplitude [31] & $\begin{array}{c}\text { The maximum of first derivative in the red edge } \\
(680 \sim 750 \mathrm{~nm})\end{array}$ & $S_{\text {red }}=\int_{680}^{750} R \prime(\lambda) d \lambda$ \\
Red edge skewness [32] & $\begin{array}{c}\text { The skewness of first derivative in the red edge } \\
(680 \sim 750 \mathrm{~nm})\end{array}$ & $s=\frac{E(X-\mu)^{3}}{\sigma^{3}}$ \\
Red edge kurtosis [32] & $\begin{array}{c}\text { The kurtosis of first derivative in the red edge } \\
(680 \sim 750 \mathrm{~nm})\end{array}$ & $k_{r e d}=\frac{E(X-\mu)^{4}}{\sigma^{4}}$ \\
Red edge position [39] & $\begin{array}{c}\text { The wavelength }(680 \sim 750 \mathrm{~nm}) \text { corresponding to } \\
\text { the maximum of the first derivative }\end{array}$ & $\lambda_{\text {red }}$ \\
\hline
\end{tabular}

Note: $R(\lambda)$ is the primary reflectance spectra at each $\lambda$ band. $R^{\prime}(\lambda)$ is the first derivative of the hyperspectral reflectance spectra in each $\lambda$ band, $\mu$ is the average value of vector $X, E(X)$ is the expected value of vector $X$, and $\sigma$ is the standard deviation of vector $X$. 


\subsubsection{Determination of Optimal Vegetation Indices}

We refer to the two most widely used combinations of hyperspectral bands, i.e., the ratio of $R_{i}$ to $R_{j}$ [40] and the normalized ratio of $\left(R_{i}-R_{j}\right)$ to $\left(R_{i}+R_{j}\right)$ [41], which are extensively applied in quantitative remote sensing of vegetation. The correlation between the most significant plant growth indicators of salt-induced Suaeda salsa response and different hyperspectral band combinations was analyzed. Two new best vegetation indices (D_RVI and D_NDVI) were found. A combination of bands in the 500-900 $\mathrm{nm}$ based on the first derivatives was selected to construct the vegetation indices using the MATLAB 2019b software [42]. The correlation coefficient and significance level matrices were obtained based on the correlation analysis. The combination of the bands with the highest significance $p<0.01$ and the highest correlation coefficient was used to establish the $D \_R V I$ and D_NDVI. The calculation formulas are shown in Equations (5) and (6):

$$
\begin{gathered}
D \_R V I=\frac{D_{x}}{D_{y}} \\
D \_N D V I=\frac{D_{a}-D_{b}}{D_{a}+D_{b}}
\end{gathered}
$$

where $D$ is the reflectance of the spectrum after the first derivative, while $x, y, a, b$ are arbitrary bands between 500-900 $\mathrm{nm}$.

\subsubsection{Statistical Analysis}

We then used Excel to calculate the mean values and standard deviations of each treatment, including its three controls (Table 2). We conducted a one-way analysis of variance (ANOVA) in SPSS 26.0 (SPSS Inc., Chicago, IL, USA) to assess the effects of the different salt treatments on plant growth indicators. We used a least-significant difference (LSD) comparison test to identify differences between individual treatments as significant $(p<0.01)$ or not. To better observe the changes in each growth indicator under different salt concentrations, we set the control group to $100 \%$, counting the other six groups according to the proportion of the control group. Figures were drawn using Adobe Photoshop 2020 (Figure 2, Adobe Systems Inc., San Jose, CA, USA), and were plotted using Origin 2020 (OriginLab Corporation, Northampton, MA, USA). An error scatter plot between the vegetation indices and red edge parameters of plant growth indicators was produced, and the fitting curve was plotted. The $\mathrm{F}$ statistic and significance level $\mathrm{p}$ were used to evaluate the response of each vegetation index and red edge parameter to the growth indicators of Suaeda salsa under various salt conditions.

Table 2. Statistical results of soil physical and chemical parameters.

\begin{tabular}{cccccc}
\hline Nutrition Items & Mean & SD & Max & Min & CV (\%) \\
\hline SSC $(\mathrm{g} / \mathrm{kg})$ & 6.646 & 4.024 & 17.600 & 0.800 & 60.550 \\
$\mathrm{pH}$ & 8.393 & 0.230 & 8.940 & 8.020 & 2.740 \\
$\mathrm{TN}(\mathrm{g} / \mathrm{kg})$ & 0.748 & 0.417 & 2.080 & 0.240 & 55.750 \\
$\mathrm{SOM}(\mathrm{g} / \mathrm{kg})$ & 13.203 & 8.328 & 45.300 & 7.000 & 63.080 \\
$\mathrm{AK}(\mathrm{mg} / \mathrm{kg})$ & 486.360 & 345.597 & 1160 & 99 & 71.060 \\
$\mathrm{TC}(\mathrm{g} / \mathrm{kg})$ & 13.955 & 7.094 & 34.800 & 4.200 & 50.830 \\
$\mathrm{NN}(\mathrm{mg} / \mathrm{kg})$ & 6.279 & 3.359 & 12.800 & 1.340 & 54.000 \\
$\mathrm{AP}(\mathrm{mg} / \mathrm{kg})$ & 10.862 & 7.284 & 27.000 & 1.900 & 67.060 \\
\hline
\end{tabular}

\section{Results}

\subsection{Habitat Soil Survey}

Table 2 shows a statistical analysis of the physical and chemical properties of topsoil samples. $\mathrm{pH}$ values ranged from 8.020 to 8.940 , with a mean of 8.393 , corresponding to saline soil. Soil salt content (SSC) values were $0.800-17.600 \mathrm{~g} / \mathrm{kg}$, with a mean of $6.646 \mathrm{~g} / \mathrm{kg}$. Based on the relationship 
between $\mathrm{g} / \mathrm{kg}$ and $\mathrm{mmol} / \mathrm{L}(100 \mathrm{mmol} / \mathrm{L}=5.844 \mathrm{~g} / \mathrm{kg})$, salt concentrations in the pot experiment were 0-35.064 g/ $/ \mathrm{kg}$, further indicating that salt concentrations of $400 \mathrm{mmol} / \mathrm{L}$ and $600 \mathrm{mmol} / \mathrm{L}$ were out of range. The aim of this experiment was mainly to determine the possible tolerance threshold for salt concentrations. Compared with the Chinese classification standard of soil nutrient contents, the soil fertility level in the study area was relatively low because of its high salt contents.

\subsection{Suaeda Salsa Response to Salt Treatemnts}

Figure 3 shows morphological indicators such as plant height, root length, number of branches, leaf succulence, aboveground FW, root FW, aboveground DW, and root DW, as well as physiological indicators such as chlorophyll $\mathrm{a}$, chlorophyll $\mathrm{b}$, total chlorophyll contents, and carotenoid content of Suaeda salsa. Compared with the control group, a salt concentration of 50-600 mmol, plant height, root length, branching number, leaf succulence, root FW, and aboveground FW with M treatment were highest, whereas plant height, root length, branching number, leaf succulence, root FW, aboveground FW, aboveground DW, root DW, and carotenoid content with E-H treatment were lowest among the salt treatments. In addition, aboveground DW, root DW, and chlorophyll content with V-L treatment were highest.
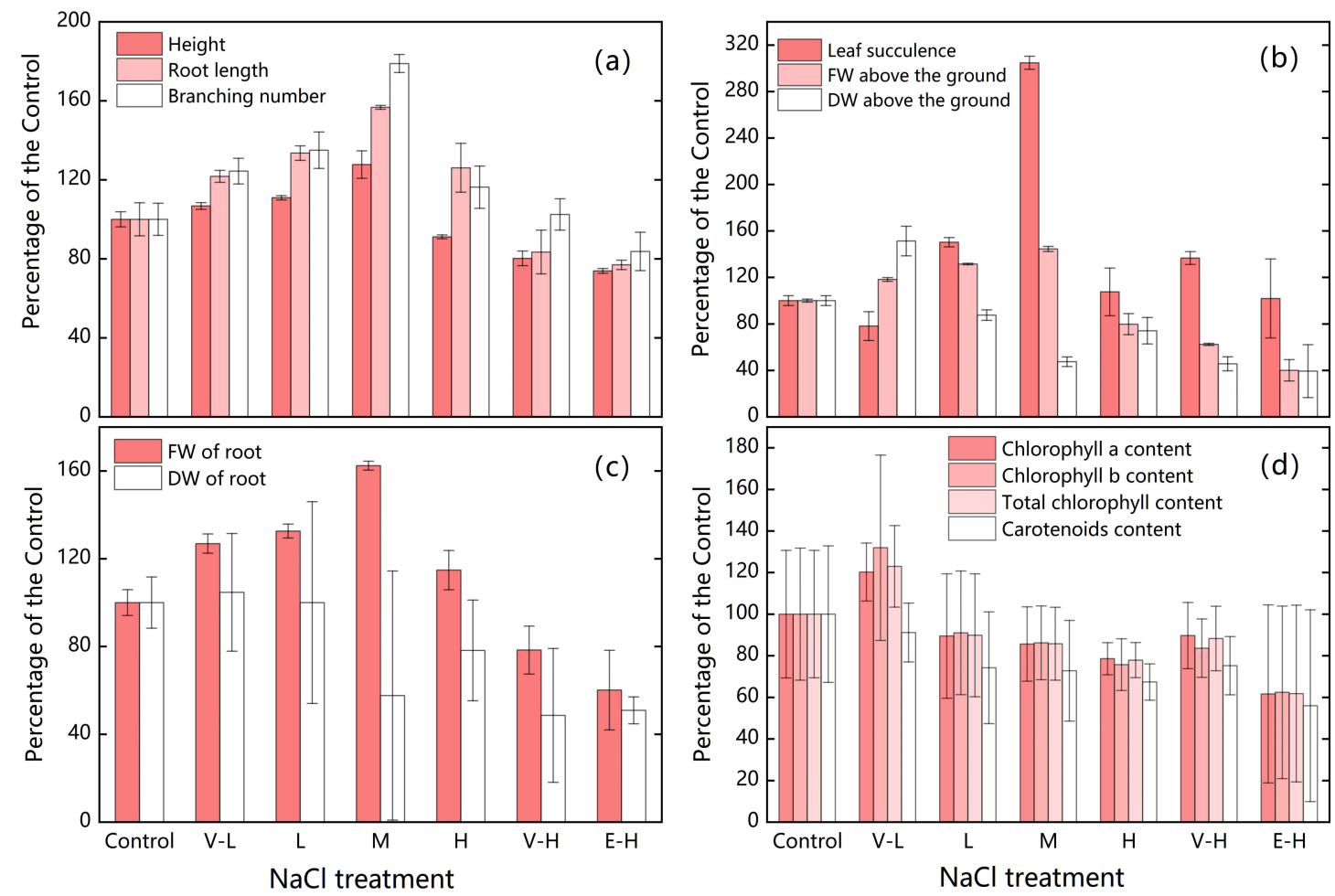

Figure 3. Effects of different salt concentration stress on various physiological indexes of Suaeda salsa. The control group was set to $100 \%$, and the remaining six groups were changed relative to the control group. The values were means \pm standard errors $(n=3)$. The real values are presented in Table 3 . ((a) plant height, root length, number of branches; (b) leaf succulence, FW above the ground, DW above the ground; (c) FW of root, DW of root; (d) chlorophyll a, chlorophyll b, total chlorophyll contents and carotenoid content of Suaeda salsa). 
Table 3. Physiological indicators for Suaeda salsa (statistics with means \pm standard errors).

\begin{tabular}{|c|c|c|c|c|c|c|c|}
\hline Indicator & Control & $50 \mathrm{mmol} / \mathrm{L}$ & $100 \mathrm{mmol} / \mathrm{L}$ & $200 \mathrm{mmol} / \mathrm{L}$ & $300 \mathrm{mmol} / \mathrm{L}$ & $400 \mathrm{mmol} / \mathrm{L}$ & $600 \mathrm{mmol} / \mathrm{L}$ \\
\hline Height (cm) & $16.83 \pm 0.64$ & $17.97 \pm 0.31$ & $18.67 \pm 0.21$ & $21.5 \pm 1.5$ & $15.33 \pm 0.15$ & $13.5 \pm 0.5$ & $\begin{array}{c}12.43 \pm \\
0.15\end{array}$ \\
\hline Root length $(\mathrm{cm})$ & $10.79 \pm 0.9$ & $13.13 \pm 0.4$ & $14.4 \pm 0.53$ & $16.9 \pm 0.17$ & $13.6 \pm 1.68$ & $9 \pm 1.00$ & $8.3 \pm 0.20$ \\
\hline Branch number & $13 \pm 1.00$ & $15 \pm 1.00$ & $16.67 \pm 1.53$ & $22 \pm 1.00$ & $14.33 \pm 1.53$ & $13 \pm 1.00$ & $10 \pm 1.00$ \\
\hline Leaf succulence & $4.54 \pm 0.19$ & $3.58 \pm 0.44$ & $6.82 \pm 0.27$ & $13.83 \pm 0.77$ & $4.95 \pm 1.00$ & $6.21 \pm 0.34$ & $4.85 \pm 1.57$ \\
\hline $\begin{array}{l}\text { FW-above } \\
\text { ground (g) }\end{array}$ & $34.48 \pm 0.43$ & $40.77 \pm 0.64$ & $45.35 \pm 0.27$ & $49.82 \pm 1.08$ & $27.49 \pm 2.49$ & $21.5 \pm 0.2$ & $13.8 \pm 1.27$ \\
\hline $\begin{array}{l}\text { DW-above } \\
\text { ground }(\mathrm{g})\end{array}$ & $7.61 \pm 0.32$ & $11.51 \pm 1.47$ & $6.66 \pm 0.3$ & $3.61 \pm 0.15$ & $5.64 \pm 0.64$ & $3.47 \pm 0.21$ & $2.99 \pm 0.68$ \\
\hline FW of roots $(\mathrm{g})$ & $5.95 \pm 0.35$ & $7.55 \pm 0.33$ & $7.89 \pm 0.25$ & $9.67 \pm 0.2$ & $6.83 \pm 0.61$ & $4.67 \pm 0.51$ & $3.58 \pm 0.65$ \\
\hline DW of roots $(\mathrm{g})$ & $1.28 \pm 0.15$ & $1.34 \pm 0.36$ & $1.28 \pm 0.59$ & $0.74 \pm 0.42$ & $1 \pm 0.23$ & $0.62 \pm 0.19$ & $0.65 \pm 0.04$ \\
\hline Chl-a (mg/L) & $2.8 \pm 0.86$ & $3.37 \pm 0.47$ & & $2.4 \pm 0.43$ & $2.2 \pm 0.17$ & $2.52 \pm 0.4$ & $1.73 \pm 0.74$ \\
\hline Chl-b (mg/L) & $0.85 \pm 0$ & $1.12 \pm 0$ & $0.77 \pm 0.23$ & $0.73 \pm 0.13$ & $0.64 \pm 0.08$ & $0.71 \pm 0.1$ & $0.53 \pm 0.22$ \\
\hline Chl-a+b (mg/L) & & $4.49 \pm$ & & & & $3.23 \pm 0.5$ & $2.26 \pm 0.96$ \\
\hline Car (mg/L) & $0.85 \pm 0.28$ & $0.78 \pm 0.11$ & $0.63 \pm 0.17$ & $0.62 \pm 0.15$ & $0.57 \pm 0.05$ & $0.64 \pm 0.09$ & $0.48 \pm 0.22$ \\
\hline
\end{tabular}

Plant height (Figure 3) significantly differed with salt treatments $\left(\mathrm{F}_{6,14}=66.43, p<0.0001\right)$. The plant height of Suaeda salsa for the $\mathrm{H}(p=0.015), \mathrm{V}-\mathrm{H}(p<0.0001)$, and E-H $(p<0.0001)$ treatments were significantly lower, whereas those for the $\mathrm{L}(p=0.005)$ and $\mathrm{M}(p<0.0001)$ treatments were significantly higher, than for the control. Root length significantly differed with salt treatment $\left(\mathrm{F}_{6,14}=38.74\right.$, $p<0.0001)$. Root lengths for the V-H $(p=0.023)$ and E-H $(p=0.023)$ treatments were significantly lower, whereas those for the V-L $(p=0.005), \mathrm{L}(p=0.00014), \mathrm{M}(p<0.0001)$, and $\mathrm{H}(p=0.001)$ treatments were significantly higher, than for the control. Branching number significantly differed with salt treatment $\left(\mathrm{F}_{6,14}=30.8, p<0.0001\right)$. Branching number for the $\mathrm{M}(p<0.0001)$ treatment was significantly higher, whereas those for the E-H $(p=0.007)$ treatments were significantly lower, than for the control. Leaf succulence differed significantly with salt treatment $\left(\mathrm{F}_{6,14}=55.84, p<0.0001\right)$; for the V-L salt treatment $(p=0.056)$, it was lower than for the control, but for the other salt treatments, it was higher.

Aboveground FW of Suaeda salsa significantly differed with salt treatment $\left(\mathrm{F}_{6,14}=371.72, p<0.0001\right)$. Aboveground FW for the V-L, L, and M salt treatments was significantly higher $(p<0.0001)$, whereas that for the $\mathrm{H}, \mathrm{V}-\mathrm{H}$, and E-H treatments was significantly lower $(p<0.0001)$, than for the control. Aboveground DW of Suaeda salsa significantly differed with salt treatment $\left(\mathrm{F}_{6,14}=58.44, p<0.0001\right)$. Aboveground DW for the $\mathrm{M}(p<0.0001), \mathrm{H}(p=0.003), \mathrm{V}-\mathrm{H}(p<0.0001)$, and $\mathrm{E}-\mathrm{H}(p<0.0001)$ treatments was lower than for the control. Root FW of Suaeda salsa significantly differed with salt treatments $\left(\mathrm{F}_{6,14}=63.98, p<0.0001\right)$. Root FW for the V-L $(p=0.001), \mathrm{L}(p<0.0001), \mathrm{M}(p<0.0001)$, and H $(p=0.03)$ treatments was higher, whereas that for the V-H $(p=0.003), \mathrm{E}-\mathrm{H}(p<0.0001)$ treatments was lower, than for the control. However, root DW of Suaeda salsa for all treatments showed no significant differences $(p>0.05)$.

Chlorophyll a $\left(\mathrm{F}_{6,56}=6.648, p<0.0001\right)$ and $\mathrm{b}\left(\mathrm{F}_{6,56}=4.771, p=0.001\right)$, total chlorophyll contents $\left(\mathrm{F}_{6,56}=6.689, p<0.0001\right)$, and carotenoid content $\left(\mathrm{F}_{6,56}=4.887, p=0.0040\right)$ differed with salt treatment. Chlorophyll a, $\mathrm{b}$, and total chlorophyll contents for the V-L $(p=0.03)$ treatment were higher, and for other treatments were lower, than the control. However, the carotenoid content for all treatments was lower than for the control.

Based on the preceding analysis, the physiological indicator of Suaeda salsa which was most sensitive to salt treatment was total chlorophyll content.

\subsection{Response of Canopy Reflectance Spectra of Suaeda Salsa to Salt Treatment}

\subsubsection{Spectral Properties of the Suaeda Salsa Canopy}

The canopy reflectance $(500-900 \mathrm{~nm})\left(\mathrm{F}_{6,2800}=13.17, p<0.0001\right)$ of Suaeda salsa and its first derivative $(500-900 \mathrm{~nm})\left(\mathrm{F}_{6,2800}=2.32, p=0.031\right)$ showed significant differences among all salt treatments (Figure 4). For Suaeda salsa, increasing salt treatments did not show a positive or negative association with reflectance at 550 and $680 \mathrm{~nm}$. However, reflectance at 550 and $680 \mathrm{~nm}$ in the control 
showed the largest reflectance, versus the lowest reflectance for the $\mathrm{M}$ treatment. The E-H treatment showed the lowest reflectance at $750 \mathrm{~nm}$, whereas the $\mathrm{L}$ treatment showed the largest, followed by the $\mathrm{V}-\mathrm{L}$ treatment. The increased level of salt ranging from $\mathrm{V}-\mathrm{L}$ to $\mathrm{H}$ treatment flattened the red edge of Suaeda salsa and lowered the first derivative of reflectance (Figure $4 \mathrm{~b}$ ), indicating that the red edge amplitude and area had decreased.
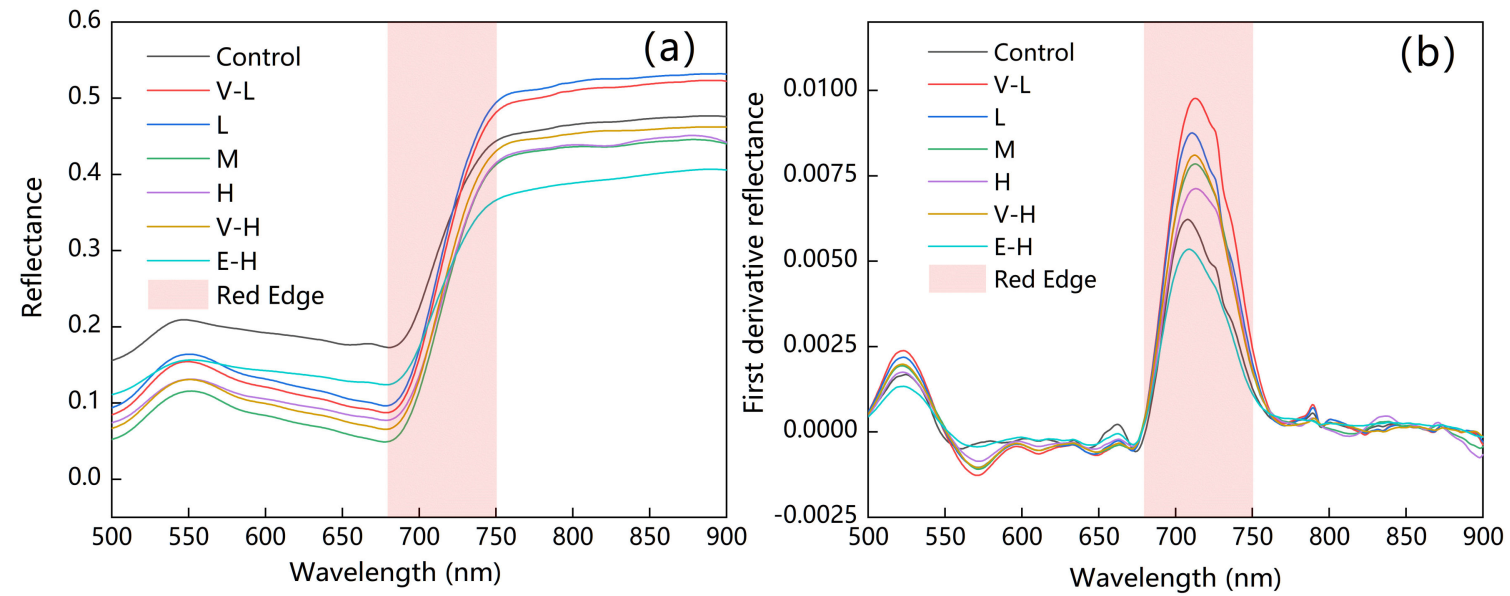

Figure 4. The original spectral curve (a) and the first derivative spectral curve (b) under different stresses with different salt concentrations.

As a result of experiment error, the growth of Suaeda salsa in the second pot experiment in the control (Figure 2B) was not the same as the other two pots. We set two types of the control groups, i.e., the mean reflectance values of three pots, but the mean values of two pots removed the second pot (Figure 2B). The results of an ANOVA analysis showed no significant difference between the two sets of reflectance $\left(\mathrm{F}_{1,800}=0.182, p=0.67\right)$.

\subsubsection{Response of Red Edge Parameters of Suaeda Salsa Canopy Reflectance to Salt Treatment}

The red edge skewness $\left(\mathrm{F}_{6,14}=1.04, p=0.44\right)$, red edge kurtosis $\left(\mathrm{F}_{6,14}=1.45, p=0.26\right)$, and red edge position $\left(\mathrm{F}_{6,14}=1.32, p=0.31\right)$ of Suaeda salsa did not show significant differences among all salt treatments (Table 4 and Figure 5). However, red edge area $\left(\mathrm{F}_{6,14}=3.18, p=0.035\right)$ and red edge amplitude $\left(\mathrm{F}_{6,14}=3.28, p=0.031\right)$ differed with salt treatments. The red edge areas for the V-L $(p=0.007)$ and $\mathrm{L}$ treatments $(p=0.042)$ were higher than that of the control. The red edge amplitude for the $\mathrm{V}-\mathrm{L}$ $(p=0.008)$ and L treatments $(p=0.043)$ showed the same patterns as the red edge area.

Table 4. Five red edged parameters under different salt treatments with means \pm standard errors $(n=3)$.

\begin{tabular}{cccccccc}
\hline Indicator & Control & $\mathbf{5 0 ~} \mathbf{~ m m o l} / \mathbf{L}$ & $\mathbf{1 0 0} \mathbf{~ m m o l} / \mathbf{L}$ & $\mathbf{2 0 0} \mathbf{~ m m o l} / \mathbf{L}$ & $\mathbf{3 0 0} \mathbf{~ m m o l} / \mathbf{L}$ & $\mathbf{4 0 0} \mathbf{~ m m o l} / \mathbf{L}$ & $\mathbf{6 0 0} \mathbf{~ m m o l} / \mathbf{L}$ \\
\hline Area & $0.27 \pm 0.07$ & $0.45 \pm 0.06$ & $0.4 \pm 0.1$ & $0.36 \pm 0.03$ & $0.34 \pm 0.07$ & $0.36 \pm 0.01$ & $0.24 \pm 0.1$ \\
Amplitude & $0.0063 \pm 0.0013$ & $0.0098 \pm 0.0014$ & $0.0088 \pm 0.0018$ & $0.0079 \pm 0.0005$ & $0.0072 \pm 0.0015$ & $0.0081 \pm 0.0003$ & $0.0056 \pm 0.002$ \\
Skewness & $-0.32 \pm 0.19$ & $-0.44 \pm 0.04$ & $-0.35 \pm 0.14$ & $-0.43 \pm 0.12$ & $-0.53 \pm 0.12$ & $-0.34 \pm 0.02$ & $-0.21 \pm 0.37$ \\
Kurtosis & $1.95 \pm 0.04$ & $1.96 \pm 0.06$ & $1.89 \pm 0.16$ & $1.88 \pm 0.15$ & $2.03 \pm 0.15$ & $1.81 \pm 0.03$ & $1.81 \pm 0.14$ \\
Position & $708 \pm 3$ & $713 \pm 2$ & $711 \pm 3$ & $713 \pm 2$ & $713 \pm 4$ & $712 \pm 2$ & $708 \pm 6$ \\
\hline
\end{tabular}

The red edge amplitude of Suaeda salsa was used to estimate the total chlorophyll content for all salt treatments by quadratic polynomial model, with $\mathrm{R}^{2}=0.762, p=0.05$ (Figure $8 \mathrm{~b}$ ). We found no correlation among red edge position, red edge area, red edge skewness, and red edge kurtosis and total chlorophyll content. 


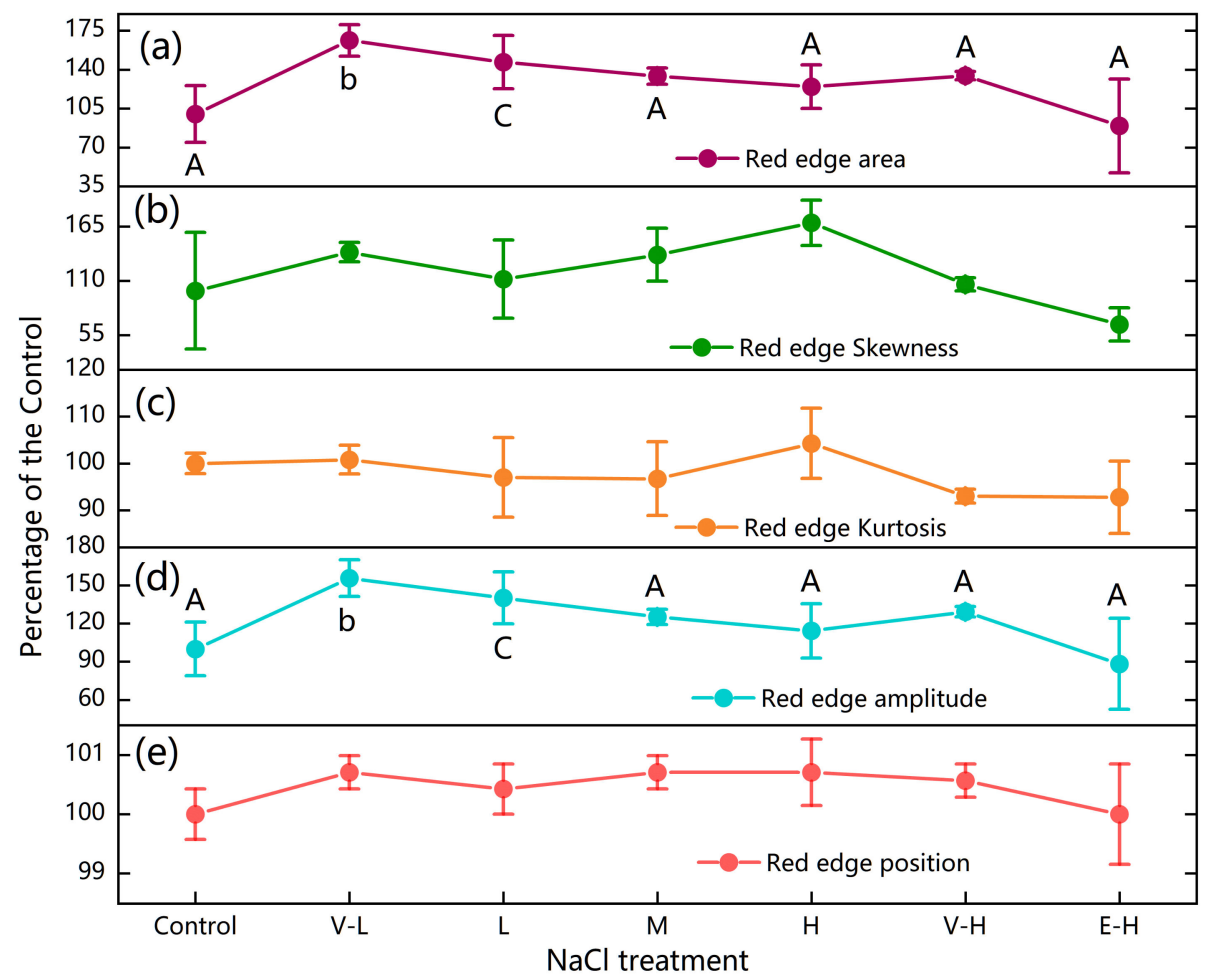

Figure 5. Trend of red edge area (a), skewness (b), kurtosis (c), amplitude (d) and position (e) of Suaeda salsa under different $\mathrm{NaCl}$ treatments. The control group was set to $100 \%$, and the remaining six groups were changed relative to the control group. The values were means \pm standard errors $(n=3)$. The real values are presented in Table 4. Capital and lower-case letters above the bars indicate significant differences at the levels of 0.05 and 0.01 . If no letter is assigned above the band, it means that this item is not significant to salt stress $(p>0.05)$. Other descriptions are as in Figure 3.

\subsubsection{Response of Sensitive Vegetation Indices to Total Chlorophyll Content}

There was strong relationship between total chlorophyll content and canopy reflectance changes in Suaeda salsa, caused by different salt conditions. Figure 6 shows the correlation coefficient and significance level matrix between hyperspectral vegetation indices and total chlorophyll content, indicating that vegetation indices $D \_R V I$ and $D \_N D V I$ from 500 to $900 \mathrm{~nm}$ were significantly related to total chlorophyll content (as shown in Figure $6 \mathrm{~b}, \mathrm{~d}, p<0.001$ ). Sensitive vegetation indices, such as $D_{-} R V I$ and $D \_N D V I$ to total chlorophyll content, were found using the following procedures. $D \_R V I, D_{x}$ was mainly concentrated in the regions of $542-549 \mathrm{~nm}, 650-659 \mathrm{~nm}, 848-856 \mathrm{~nm}, 873 \mathrm{~nm}$, and $897 \mathrm{~nm}$, whereas $D_{y}$ was primarily focused in the regions of $543-547 \mathrm{~nm}, 648-661 \mathrm{~nm}, 786-793 \mathrm{~nm}$, and $845-847 \mathrm{~nm}$ (Figure 6a,b). The coefficient $a$ for $D \_N D V I$ was mainly concentrated in the regions of $624-626 \mathrm{~nm}, 639-645 \mathrm{~nm}, 780-801 \mathrm{~nm}, 845-857 \mathrm{~nm}$, and $873 \mathrm{~nm}$. The coefficient $b$ was determined from the regions of $624-626 \mathrm{~nm}, 780-781 \mathrm{~nm}, 781-793 \mathrm{~nm}, 791-801 \mathrm{~nm}$, and 845-848 nm (Figure $6 \mathrm{c}, \mathrm{d}$ ). Then, six sensitive vegetation indices (VIs) were retrieved as $\mathrm{D}_{655} / \mathrm{D}_{546}, \mathrm{D}_{873} / \mathrm{D}_{846}, \mathrm{D}_{854} / \mathrm{D}_{792},\left(\mathrm{D}_{645}\right.$ $\left.\mathrm{D}_{791}\right) /\left(\mathrm{D}_{645}+\mathrm{D}_{791}\right),\left(\mathrm{D}_{792}-\mathrm{D}_{854}\right) /\left(\mathrm{D}_{792}+\mathrm{D}_{854}\right)$, and $\left(\mathrm{D}_{781}-\mathrm{D}_{625}\right) /\left(\mathrm{D}_{781}+\mathrm{D}_{625}\right)$. 

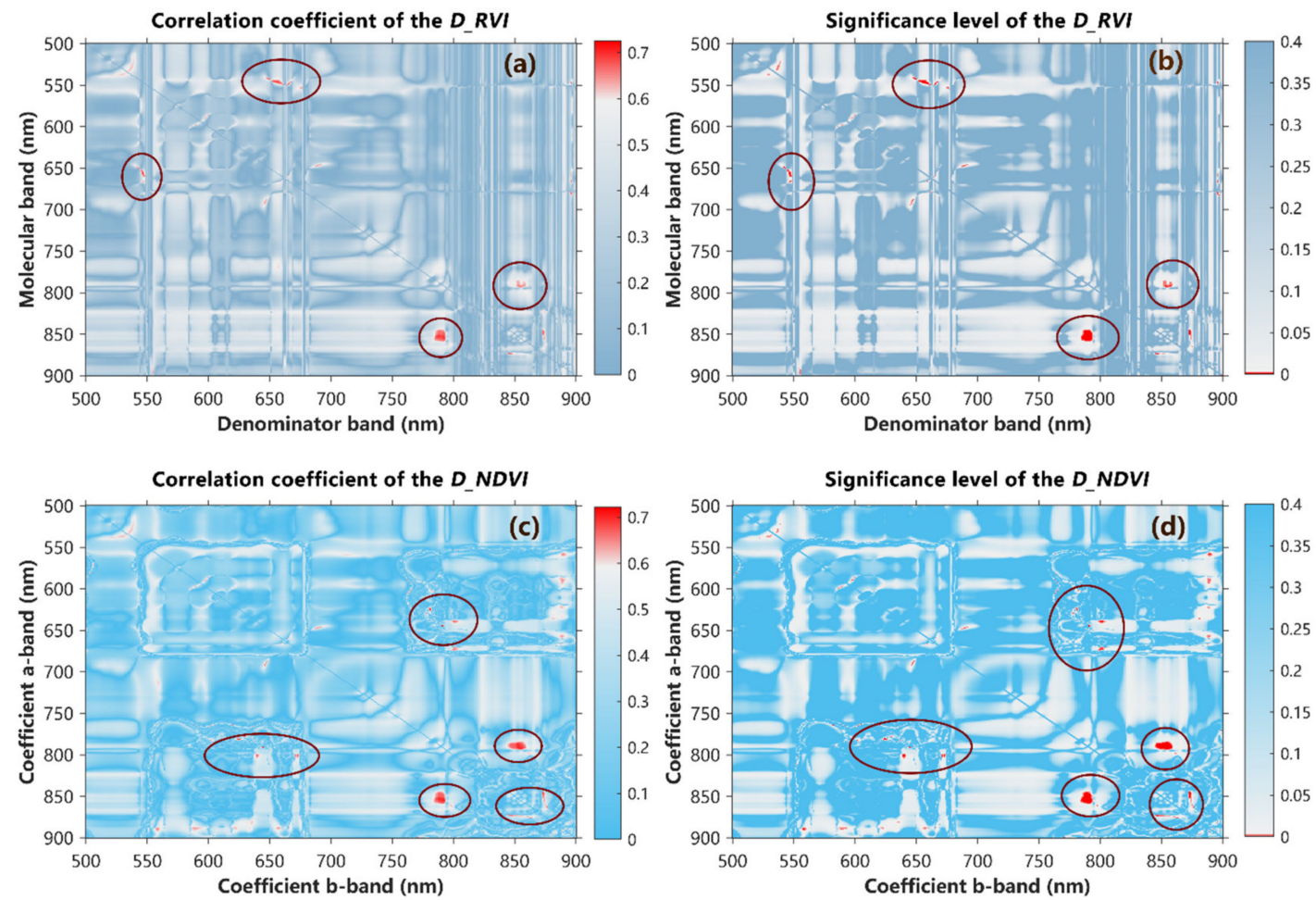

Figure 6. The correlation coefficient matrix (a) and significance level matrix (b) between the ratio vegetation indices based on derivative reflectance $\left(D \_R V I\right)$ and total chlorophyll content, and the correlation coefficient matrix (c) and significance level matrix (d) of normalized difference vegetation indices (NDVI) based on derivative reflectance (D_NDVI) and total chlorophyll content. The red regions indicate the significance level $p<0.001$.

Figure 7 shows the ANOVA result between the 6-VIs and salt treatments. Three vegetation indices, i.e., $\mathrm{D}_{655} / \mathrm{D}_{546}\left(\mathrm{~F}_{6,14}=5.083, p=0.006\right), \mathrm{D}_{854} / \mathrm{D}_{792}\left(\mathrm{~F}_{6,14}=10.622, p=0.00012\right)$, and $\left(\mathrm{D}_{792}-\mathrm{D}_{854}\right) /\left(\mathrm{D}_{792}+\right.$ $\left.\mathrm{D}_{854}\right)\left(\mathrm{F}_{6,14}=6.74, p=0.002\right)$ significantly differed with salt conditions $(p<0.01)$ (Table 5 and Figure 7). Two vegetation indices, $\mathrm{D}_{655} / \mathrm{D}_{546}$ and $\mathrm{D}_{854} / \mathrm{D}_{792}$, for the $\mathrm{E}-\mathrm{H}$ treatment were lower than for the control, whereas $\mathrm{D}_{655} / \mathrm{D}_{546}$ for the V-L treatment was higher than for the control $(p<0.01)$.

Table 5. Optimal VIs under different salt treatments with means \pm standard errors $(n=3)$.

\begin{tabular}{cccccccc}
\hline Index & Control & $\mathbf{5 0 ~} \mathbf{~ m m o l} / \mathbf{L}$ & $\mathbf{1 0 0} \mathbf{~ m m o l} / \mathbf{L}$ & $\mathbf{2 0 0} \mathbf{~ m m o l} / \mathbf{L}$ & $\mathbf{3 0 0} \mathbf{~ m m o l} / \mathbf{L}$ & $\mathbf{4 0 0} \mathbf{~ m m o l} / \mathbf{L}$ & $\mathbf{6 0 0} \mathbf{~ m m o l} / \mathbf{L}$ \\
\hline $\mathrm{D}_{655} / \mathrm{D}_{546}$ & $-1.12 \pm 0.41$ & $-1.5 \pm 0.07$ & $-1.2 \pm 0.28$ & $-1.17 \pm 0.08$ & $-0.96 \pm 0.15$ & $-1.27 \pm 0.08$ & $-0.62 \pm 0.16$ \\
$\mathrm{D}_{873} / \mathrm{D}_{846}$ & $0.94 \pm 0.21$ & $1.18 \pm 0.16$ & $1.06 \pm 0.18$ & $0.93 \pm 0.11$ & $0.86 \pm 0.03$ & $0.83 \pm 0.1$ & $0.77 \pm 0.22$ \\
$\mathrm{D}_{854} / \mathrm{D}_{792}$ & $0.42 \pm 0.19$ & $0.3 \pm 0.08$ & $0.38 \pm 0.19$ & $0.57 \pm 0.06$ & $0.62 \pm 0.12$ & $0.42 \pm 0.06$ & $0.98 \pm 0.06$ \\
$\left(\mathrm{D}_{645}-\mathrm{D}_{791}\right) /$ & $-5.8 \pm 7.6$ & $-38.11 \pm 75.07$ & $-14.14 \pm 17.65$ & $5.17 \pm 4$ & $8.5 \pm 2.56$ & $6.46 \pm 3.65$ & $24.56 \pm 31.87$ \\
$\left(\mathrm{D}_{645}+\mathrm{D}_{791}\right)$ & & & & & & \\
$\left(\mathrm{D}_{792}-\mathrm{D}_{854}\right) /$ & $0.43 \pm 0.2$ & $0.54 \pm 0.09$ & $0.47 \pm 0.18$ & $0.28 \pm 0.04$ & $0.24 \pm 0.1$ & $0.41 \pm 0.06$ & $0.01 \pm 0.03$ \\
$\left(\mathrm{D}_{792}+\mathrm{D}_{854}\right)$ & & & & & \\
$\left(\mathrm{D}_{781}-\mathrm{D}_{625}\right) /$ & $6.55 \pm 10.39$ & $31.76 \pm 38.2$ & $-19.35 \pm 0.35$ & $-4.54 \pm 1.92$ & $-4.19 \pm 2.63$ & $-4.59 \pm 2.11$ \\
$\left(\mathrm{D}_{781}+\mathrm{D}_{625}\right)$ & & & & & \\
\hline
\end{tabular}




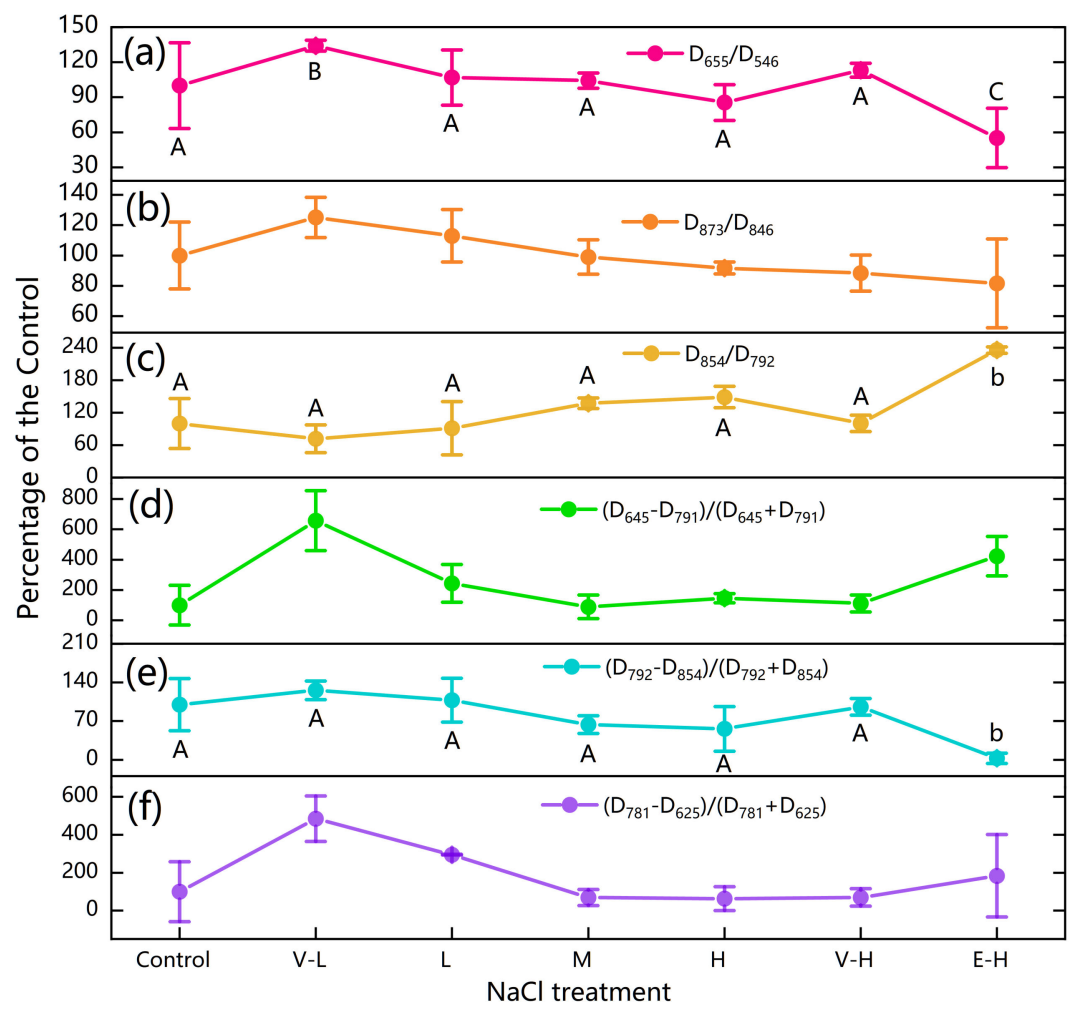

Figure 7. Changes in the sensitive vegetation indices $\mathrm{D}_{655} / \mathrm{D}_{546}(\mathbf{a}), \mathrm{D}_{873} / \mathrm{D}_{846}(\mathbf{b}), \mathrm{D}_{854} / \mathrm{D}_{792}(\mathbf{c}),\left(\mathrm{D}_{645}\right.$ $\left.-\mathrm{D}_{791}\right) /\left(\mathrm{D}_{645}+\mathrm{D}_{791}\right)(\mathbf{d}),\left(\mathrm{D}_{792}-\mathrm{D}_{854}\right) /\left(\mathrm{D}_{792}+\mathrm{D}_{854}\right)(\mathbf{e})$ and $\left(\mathrm{D}_{781}-\mathrm{D}_{625}\right) /\left(\mathrm{D}_{781}+\mathrm{D}_{625}\right)(\mathbf{f})$ of Suaeda salsa under different $\mathrm{NaCl}$ treatments. The control group was set to $100 \%$, and the remaining six groups were changed relative to the control. The values were means \pm standard errors $(n=3)$. Capital and lower-case letters above the bars indicate significant differences at the levels of 0.05 and 0.01 . If no letter is assigned above the bars, it means that this item was not significant to salt treatments $(p>0.05)$. The real values are presented in Table 5. Other descriptions are as in Figure 3.

Vegetation indices $\mathrm{D}_{655} / \mathrm{D}_{546}, \mathrm{D}_{854} / \mathrm{D}_{792}$, and $\left(\mathrm{D}_{792}-\mathrm{D}_{854}\right) /\left(\mathrm{D}_{792}+\mathrm{D}_{854}\right)$ of Suaeda salsa were used to estimate the total chlorophyll content among all salt treatments using a quadratic polynomial model, with $\mathbf{R}^{2}=0.97(p=0.000876), \mathbf{R}^{2}=0.966(p=0.0011)$, and $\mathbf{R}^{2}=0.96(p=0.0013)$, respectively (Figure $9 \mathrm{a}, \mathrm{c}, \mathrm{e})$.

\section{Discussion}

\subsection{Effects on Plant Parameters of Suaeda Salsa}

Soil salinity is a major abiotic stressor that negatively affects plant growth and ecosystem health in coastal wetlands [43]. Leaf succulence allows Suaeda salsa to adapt to saline environments, with parenchyma cells multiplying so that volume also increases, allowing the plant to absorb and store large quantities of water. As a result, the water content in the unit volume of tissue increases, diluting the salt that the plant absorbs from the soil and maintaining its normal physiological activities [44-47].

Our study demonstrated that compared with the control, the FW, root length, branching number, and height of Suaeda salsa clearly increased with increasing salt treatments ranging from V-L to M, peaking with the $\mathrm{M}$ treatment. However, these parameters decreased slightly with further increased salt treatments ranging from $\mathrm{M}$ to $\mathrm{E}-\mathrm{H}$ (Figure $3 \mathrm{a}-\mathrm{c}$ ). These results are consistent with those of many previous studies [48-50]. Our results suggest that a salt concentration of around $200 \mathrm{mmol} / \mathrm{L}$ $(11.688 \mathrm{~g} / \mathrm{kg})$ is optimal for growth of Suaeda salsa. This finding is consistent with the field survey situation and very closely resembles salt soil concentrations of $207 \mathrm{mmol} / \mathrm{L}$, which are suitable for growth of Suaeda salsa [51]. When salt concentrations in the soil exceed $275 \mathrm{mmol} / \mathrm{L}$, the growth of 
Suaeda salsa is inhibited [52]. The leaf succulence of Suaeda salsa reached its peak value with the M salt treatment, perhaps because Suaeda salsa increased the thickness of thin-walled tissue cells, expanded in volume, and increased leaf succulence level to absorb additional water with which to dilute salt concentrations, maintaining its growth; this is potentially the reason why the morphological indicators of Suaeda salsa peaked at a $200 \mathrm{mmol} / \mathrm{L}$ salt concentration in our study; however, excessively high salt concentrations will obviously weaken this phenomenon [53-55].

Changes in chlorophyll content are among the most important physiological indicators for monitoring plant stress. The response of the chlorophyll content to plant stress is closely related [56-58]. In our study, it was found that the chlorophyll and carotenoid contents gradually decreased with increasing salt concentrations (from V-L to $\mathrm{H}$ ), and reached the highest values for the V-L treatment (Figure 3d). This suggests that an appropriate salt concentration in the soil can improve the growth of Suaeda salsa. Our result is similar to that of Guan [10], who determined that the contents of chlorophyll $a, b$, total chlorophyll, and carotenoid decreased significantly with increasing soil salinity and water table levels.

Figure 3 shows that the response characteristics of physiological indicators were different from those of the other morphological indicators of Suaeda salsa, such as root length and FW. This could be explained by the fact that the chloroplast and mitochondria of Suaeda salsa would first be damaged by sodium ions and then form reactive oxygen species (ROS) with increasing salt concentrations [59]. The antioxidant response system (ARS) in plant cells reached a balance by removing ROS to protect cells from oxidative damage [60]. However, high salt concentrations $(>200 \mathrm{mmol} / \mathrm{L})$ will break this balance and inhibit the growth of Suaeda salsa. It also indirectly indicates that this salt-tolerant plant can grow normally with a salt concentration of $50-200 \mathrm{mmol} / \mathrm{L}$. Thus, a Suaeda salsa community could ameliorate soil salinization in degraded coastal wetlands.

\subsection{Mechanisms and Potential for Monitoring Plant Stress Using Red Edge and Sensitive Vegetation Indices}

An ANOVA of the red edge parameters and salt treatment found that the responses of the former to the different salt conditions were not ideal (Table 4 and Figure 5). Only red edge area and amplitude significantly differed with salt treatment. This result was also supported by scatter plots and fitting trendlines of red edge parameters and chlorophyll content, as shown in Figure 8, with only red edge amplitude having a relatively good-fitting trend (RMSE $=0.521)$. Our results differed from those of many previous studies that used the red edge parameters of vegetation to monitor changes to vegetation under salt stress [61,62], perhaps reflecting the various responses of the red edge parameters for different plant types and stressors. It is also possible that red edge parameters are suitable for detecting plant biophysical and biochemical parameters. Zhu et al., for example, used red edge area and slope to monitor plant response to phenanthrene [26].

This study also found that the optimal wavelengths ( $x, y$, a, and $b$ in Equations (5) and (6)) to compute $D \_R V I$ and $D \_N D V I$ were mainly concentrated between 786-793 nm and 848-856 nm (Figure 6). An analysis of the response of sensitive vegetation indices $D_{854} / D_{792}$ and $\left(D_{792}-D_{854}\right) /\left(D_{792}\right.$ $+\mathrm{D}_{854}$ ) to salt treatment supports this finding (Figure 8, Figure 9, and Figure 10). However, no valid band combinations were found in the red edge range (i.e., $680-750 \mathrm{~nm}$ ). This finding differed from that of some scholars, who used the red edge band to construct vegetation indices to estimate total chlorophyll content $[39,63]$. On the other hand, some others have reported that vegetation indices constructed in the near-infrared band were highly correlated with total chlorophyll content $[64,65]$. Although the vegetation indices constructed in the near-infrared band were highly accurate for the inversion of chlorophyll content $[66,67]$ in the salt treatment in our study, this needs to be further refined in the future study. 

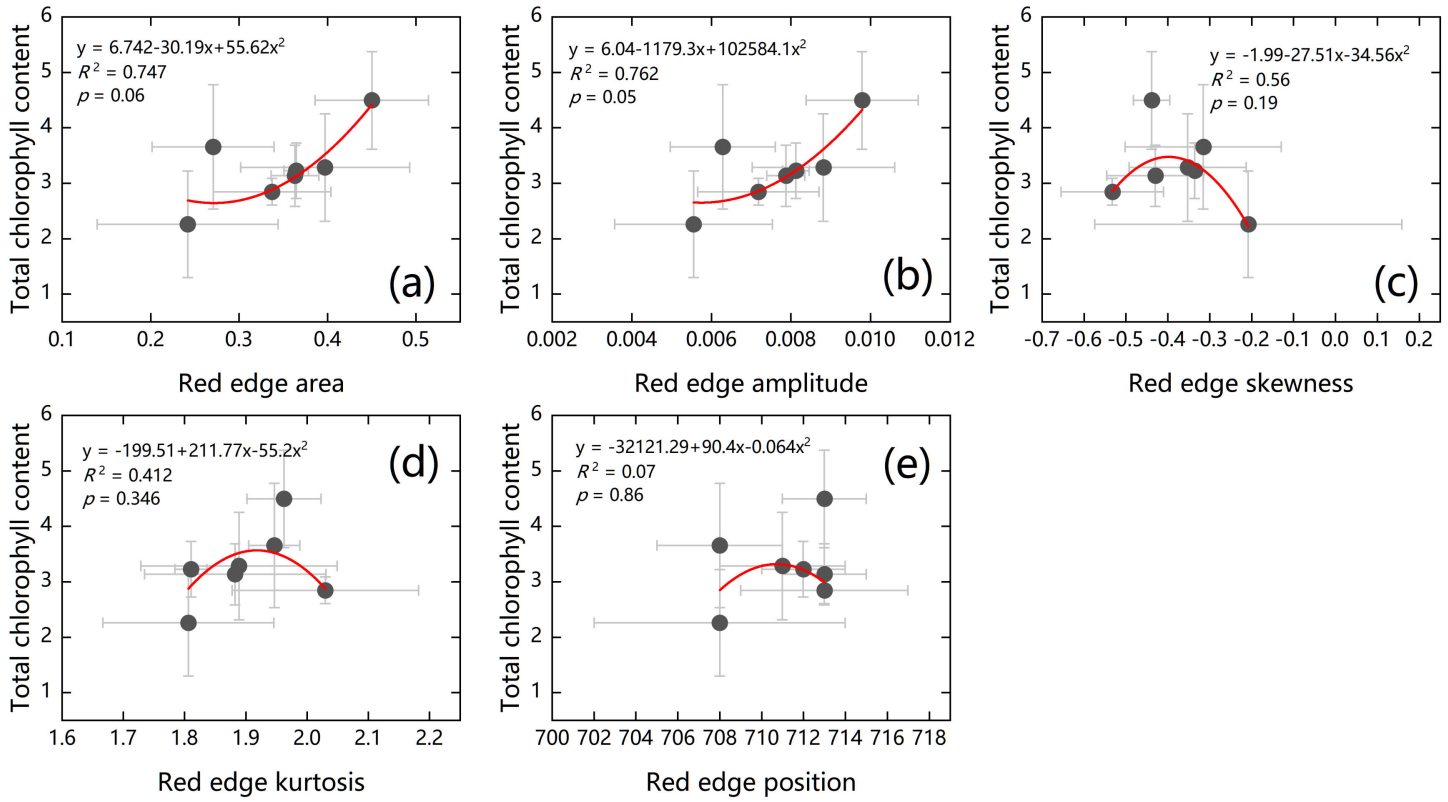

Figure 8. Relationship between total chlorophyll content of Suaeda salsa and measured red edge area (a), amplitude (b), skewness (c), kurtosis (d), position (e). The error bars represent the standard error of the mean of the chlorophyll and various red edge parameters $(n=3)$. The red curve represents a quadratic polynomial fit.
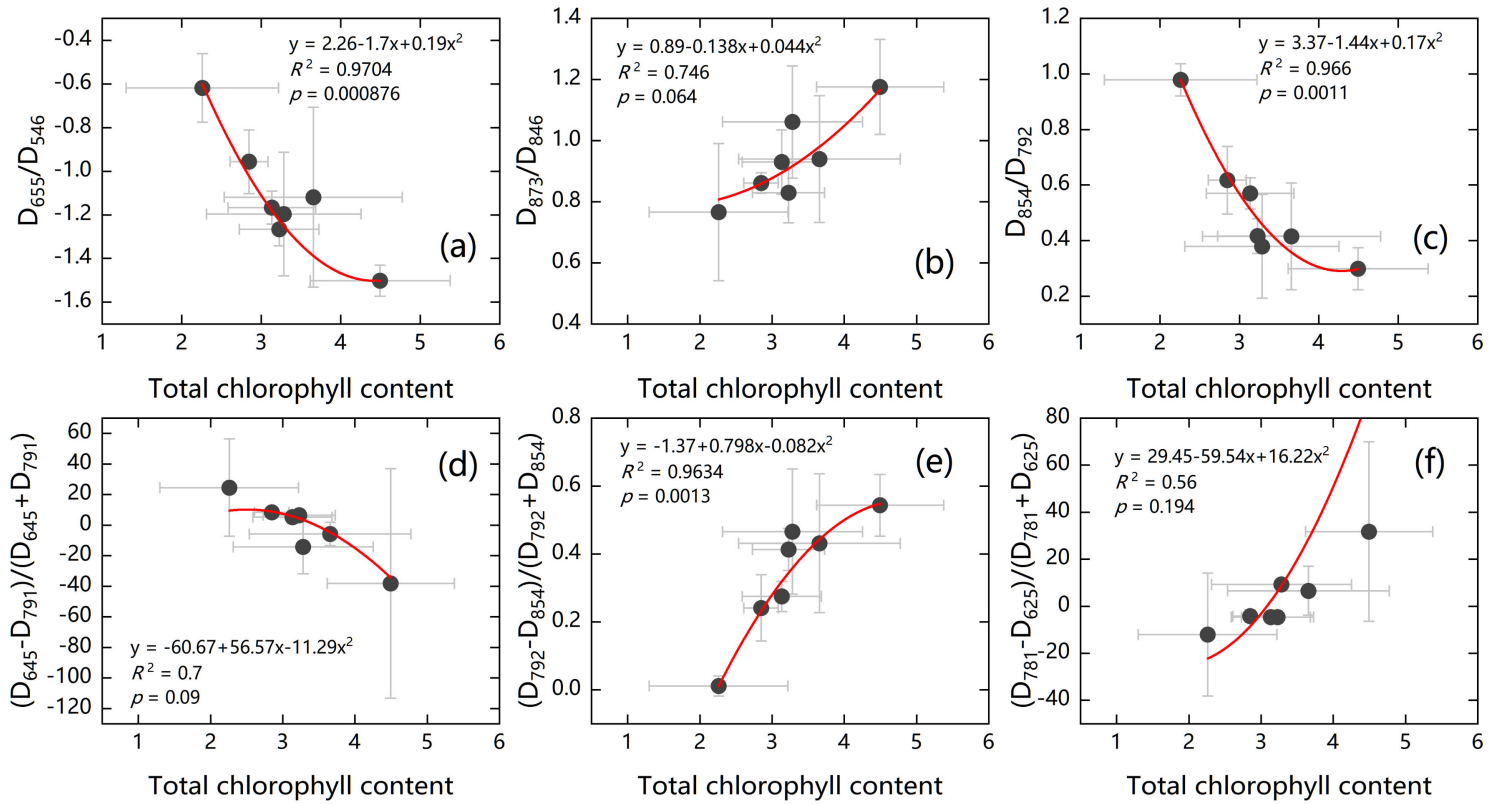

Figure 9. The relationship between the chlorophyll content of Suaeda salsa and the best vegetation indices $\mathrm{D}_{655} / \mathrm{D}_{546}(\mathbf{a}), \mathrm{D}_{873} / \mathrm{D}_{846}(\mathbf{b}), \mathrm{D}_{854} / \mathrm{D}_{792}(\mathbf{c}),\left(\mathrm{D}_{645}-\mathrm{D}_{791}\right) /\left(\mathrm{D}_{645}+\mathrm{D}_{791}\right)(\mathbf{d}),\left(\mathrm{D}_{792}-\mathrm{D}_{854}\right) /\left(\mathrm{D}_{792}+\right.$ $\left.D_{854}\right)(\mathbf{e})$ and $\left(D_{781}-D_{625}\right) /\left(D_{781}+D_{625}\right)(\mathbf{f})$. The error bars represent the standard error of the mean of total chlorophyll content and various red edge parameters $(n=3)$. The red curve represents a quadratic polynomial fit. 

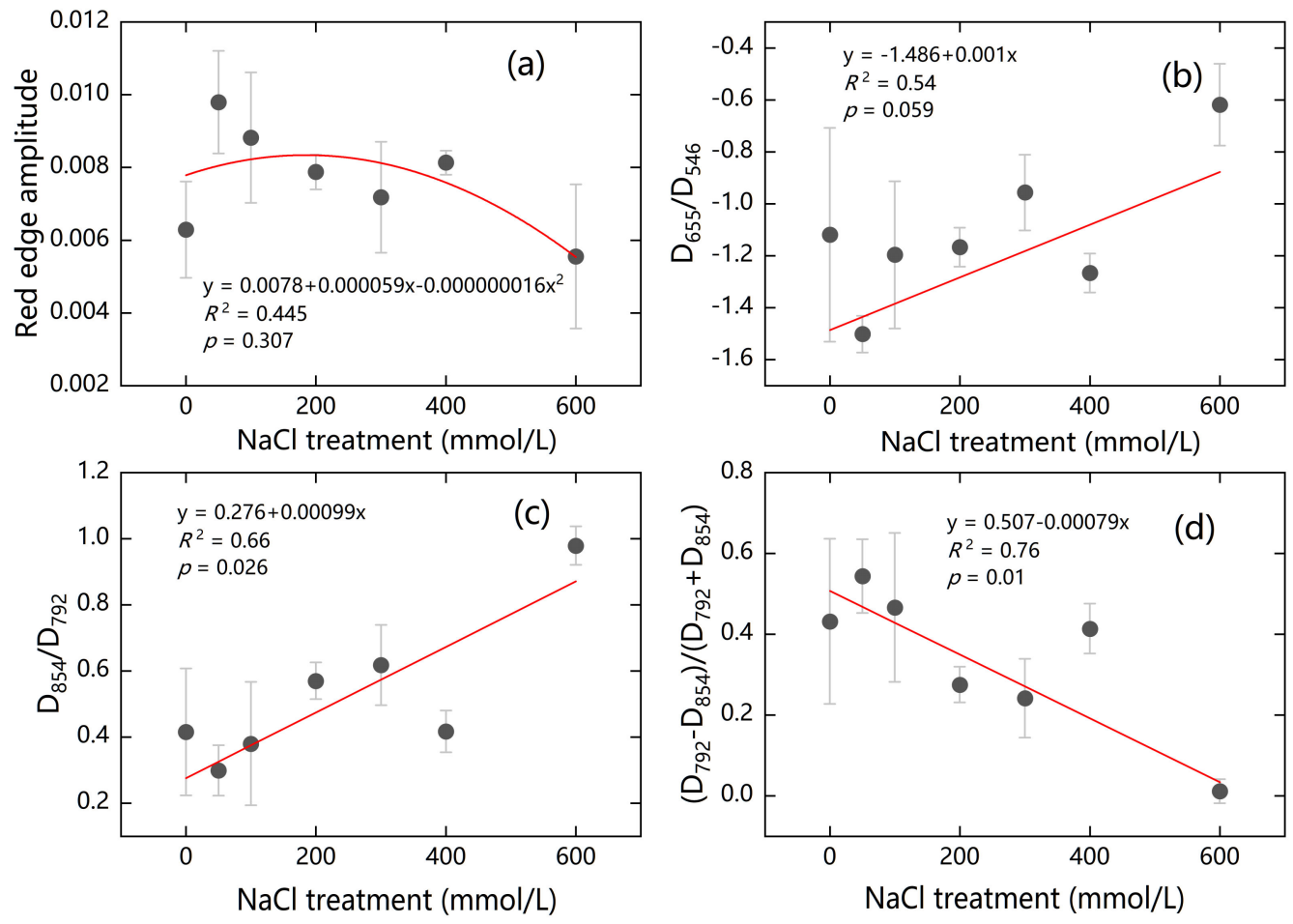

Figure 10. Relationship between applied salt concentration and red edge amplitude (a) and optimal vegetation indices $D_{655} / D_{546}(\mathbf{b}), D_{854} / D_{792}(\mathbf{c})$ and $\left(D_{792}-D_{854}\right) /\left(D_{792}+D_{854}\right)(\mathbf{d})$. Error bars represent the standard error of the red edge amplitude and the average of the best vegetation indices $(n=3)$.

The red curve represents the best fit line.

In the present study, vegetation indices $D \_R V I$ and $D \_N D V I$ were more suitable for than the red edge parameters of Suaeda salsa for estimating the total chlorophyll content under different salt conditions (Figure 7). In particular, the three vegetation indices, $\mathrm{D}_{655} / \mathrm{D}_{546}, \mathrm{D}_{854} / \mathrm{D}_{792}$, and $\left(\mathrm{D}_{792}\right.$ $\left.D_{854}\right) /\left(D_{792}+D_{854}\right)$, effectively simulated total chlorophyll content (Figure 9). Figure 10 shows that two vegetation indices, $D_{854} / D_{792}$ and $\left(D_{792}-D_{854}\right) /\left(D_{792}+D_{854}\right)$, were sensitive to salt treatment, with indices $D \_R V I$ and $D \_N D V I$ showing significantly better capacity than the red edge parameters for estimating salt treatments and total chlorophyll content. In addition, vegetation indices that were sensitive to total chlorophyll content showed potential for simulating soil salt concentration. Because changes in soil salt can affect plant growth indicators, influencing vegetation reflectance spectra, vegetation indices show promise for monitoring vegetation response to salt stress; this is perhaps the primary reason why many previous studies have used multiple vegetation indices to monitor vegetation changes [68-70] in coastal wetlands.

\section{Conclusions}

Applying seven different salt concentrations, we analyzed the response of plant growth indicators and canopy reflectance to different salt treatments in coastal wetlands. Taking the Dafeng Elk National Nature Reserve (DENNR) in China as a case study, we collected Suaeda salsa seedlings and divided them into seven groups to conduct potted experiments, using ANOVA analysis to study the responses of plant growth indicators such as height, FW, DW, and chlorophyll content. We assessed the responses of Suaeda salsa canopy reflectance to salt treatment using red edge parameters and sensitive vegetation indices. We also estimated the total chlorophyll content which was most sensitive to salt conditions using red edge parameters and vegetation indices. Our conclusions were as follows:

(1) Among all physiological indicators, the total chlorophyll content of Suaeda salsa showed the best response to the salt treatment. 
(2) The red edge parameters and vegetation indices that were sensitive to salt treatments were red edge area, red edge amplitude, $\mathrm{D}_{854} / \mathrm{D}_{792}$, and $\left(\mathrm{D}_{792}-\mathrm{D}_{854}\right) /\left(\mathrm{D}_{792}+\mathrm{D}_{854}\right)$.

(3) Compared with the red edge parameters, the vegetation indices D_RVI and D_NDVI strongly correlated with total chlorophyll content for the different salt treatments $(p<0.01)$. The vegetation indices constructed based on the first derivative reflectance of the canopy spectra in the near-infrared band combination between 786-793 nm and 848-856 nm correlated best with the chlorophyll content of Suaeda salsa for the different salt treatments, especially for vegetation indices $\mathrm{D}_{854} / \mathrm{D}_{792}, \mathrm{D}_{655} / \mathrm{D}_{546}$, and $\left(\mathrm{D}_{792}-\mathrm{D}_{854}\right) /\left(\mathrm{D}_{792}+\mathrm{D}_{854}\right)$.

Multiple factors, such as groundwater and salinity, may affect the growth and spectral characteristics of Suaeda salsa. In future studies, Suaeda salsa's mechanism of hyperspectral response to water table and salt stress should be further studied in pot experiments or in the field.

Author Contributions: X.L. R.W. and S.Z. conceived and designed the experiment; S.Z. and R.W. performed the experiments and analyzed the data; X.L. improved the data analysis and supervised the experiment; X.L., S.Z., Y.T. and Y.L. wrote the draft; J.T. and Y.Z. supervised the research, reviewed and edited the draft. All authors have read and agreed to the published version of the manuscript.

Funding: This study was financially supported by the National Natural Science Foundation (U1901215 and 41506106), a project funded by the Priority Academic Program Development of Jiangsu Higher Education Institutions (PAPD) and the Postgraduate Research \& Practice Innovation Program of Jiangsu Province (SJCX19_0962).

Acknowledgments: Field measurements and data collection from the Dafeng Elk National Nature Reserve in China are highly appreciated.

Conflicts of Interest: The authors declare no conflict of interest.

\section{References}

1. Taddeo, S.; Dronova, I.; Depsky, N. Spectral vegetation indices of wetland greenness: Responses to vegetation structure, composition, and spatial distribution. Remote Sens. Environ. 2019, 234, 111467. [CrossRef]

2. Cui, B.; He, Q.; Zhao, X. Ecological thresholds of Suaeda salsa to the environmental gradients of water table depth and soil salinity. Acta Ecol. Sin. 2008, 28, 1408-1418. [CrossRef]

3. Zheng, C.; Jiang, D.; Liu, F.; Dai, T.; Jing, Q.; Cao, W. Effects of salt and waterlogging stresses and their combination on leaf photosynthesis, chloroplast ATP synthesis, and antioxidant capacity in wheat. Plant Sci. 2009, 176, 575-582. [CrossRef] [PubMed]

4. Saqib, M.; Akhtar, J.; Qureshi, R.H. $\mathrm{Na}^{+}$exclusion and salt resistance of wheat (Triticum aestivum) in saline-waterlogged conditions are improved by the development of adventitious nodal roots and cortical root aerenchyma. Plant Sci. 2005, 169, 125-130. [CrossRef]

5. Wang, B.; Lüttge, U.; Ratajczak, R. Specific regulation of SOD isoforms by NaCl and osmotic stress in leaves of the $\mathrm{C}_{3}$ halophyte Suaeda salsa L. J. Plant Physiol. 2004, 161, 285-293. [CrossRef]

6. Li, J.; Hussain, T.; Feng, X.; Guo, K.; Chen, H.; Yang, C.; Liu, X. Comparative study on the resistance of Suaeda glauca and Suaeda salsa to drought, salt, and alkali stresses. Ecol. Eng. 2019, 140, 105593. [CrossRef]

7. An, Y.; Gao, Y.; Zhang, Y.; Tong, S.; Liu, X. Early establishment of Suaeda salsa population as affected by soil moisture and salinity: Implications for pioneer species introduction in saline-sodic wetlands in Songnen Plain, China. Ecol. Indic. 2019, 107, 105654. [CrossRef]

8. Li, X.; Zhang, X.; Wang, X.; Yang, X.; Cui, Z. Bioaugmentation-assisted phytoremediation of lead and salinity co-contaminated soil by Suaeda salsa and Trichoderma asperellum. Chemosphere 2019, 224, 716-725. [CrossRef]

9. Song, J.; Fan, H.; Zhao, Y.; Jia, Y.; Du, X.; Wang, B. Effect of salinity on germination, seedling emergence, seedling growth and ion accumulation of a euhalophyte Suaeda salsa in an intertidal zone and on saline inland. Aquat. Bot. 2008, 88, 331-337. [CrossRef]

10. Guan, B.; Yu, J.; Wang, X.; Fu, Y.; Kan, X.; Lin, Q.; Han, G.; Lu, Z. Physiological Responses of Halophyte Suaeda salsa to Water Table and Salt Stresses in Coastal Wetland of Yellow River Delta. Clean Soil Air Water. 2011, 39, 1029-1035. [CrossRef] 
11. Bueno, M.; Lendínez, M.L.; Calero, J.; Del Pilar Cordovilla, M. Salinity responses of three halophytes from inland saltmarshes of Jaén (Southern Spain). Flora. Morphol. Geobotanik Oekophysiol. 2020, 266, 151589. [CrossRef]

12. Ferreira, J.F.S.; Liu, X.; Suarez, D.L. Fruit yield and survival of five commercial strawberry cultivars under field cultivation and salinity stress. Sci. Hortic. Amsterdam 2019, 243, 401-410. [CrossRef]

13. Chen, B.; Sun, Z. Effects of nitrogen enrichment on variations of sulfur in plant-soil system of Suaeda salsa in coastal marsh of the Yellow River estuary, China. Ecol. Indic. 2020, 109, 105797. [CrossRef]

14. Zhang, S.; Bai, J.; Wang, W.; Huang, L.; Zhang, G.; Wang, D. Heavy metal contents and transfer capacities of Phragmites australis and Suaeda salsa in the Yellow River Delta, China. Phys. Chem. Earth Parts A B C 2018, 104, 3-8. [CrossRef]

15. Sun, Z.; Mou, X.; Zhang, D.; Sun, W.; Hu, X.; Tian, L. Impacts of burial by sediment on decomposition and heavy metal concentrations of Suaeda salsa in intertidal zone of the Yellow River estuary, China. Mar. Pollut. Bull. 2017, 116, 103-112. [CrossRef]

16. Mou, X.J.; Sun, Z.G. Effects of sediment burial disturbance on seedling emergence and growth of Suaeda salsa in the tidal wetlands of the Yellow River estuary. J. Exp. Mar. Biol. Ecol. 2011, 409, 99-106. [CrossRef]

17. Liu, P.; Wang, Q.; Bai, J.; Gao, H.; Huang, L.; Xiao, R. Decomposition and return of C and N of plant litters of Phragmites australis and Suaeda salsa in typical wetlands of the Yellow River Delta, China. Proc. Environ. Sci. 2010, 2, 1717-1726. [CrossRef]

18. Zhang, G.S.; Wang, R.Q.; Song, B.M. Plant community succession in modern Yellow River Delta, China. J. Zhejiang Univ. Sci. B 2007, 8, 540-548. [CrossRef]

19. Alexander, F.H.G.; Vane, G.; Solomon, J.E.; Rock, B.N. Imaging Spectrometry for Earth Remote Sensing. Science 1985, 228, 1147-1153. [CrossRef]

20. Yi, Q.; Huang, J.; Wang, F.; Wang, X.; Liu, Z. Monitoring Rice Nitrogen Status Using Hyperspectral Reflectance and Artificial Neural Network. Environ. Sci. Technol. 2007, 41, 6770-6775. [CrossRef]

21. Zhang, H.; Hu, H.; Zhang, X.; Wang, K.; Song, T.; Zeng, F. Detecting Suaeda salsa L. chlorophyll fluorescence response to salinity stress by using hyperspectral reflectance. Acta Physiol. Plant. 2012, 34, 581-588. [CrossRef]

22. Li, G.; Wan, S.; Zhou, J.; Yang, Z.; Qin, P. Leaf chlorophyll fluorescence, hyperspectral reflectance, pigments content, malondialdehyde and proline accumulation responses of castor bean (Ricinus communis L.) seedlings to salt stress levels. Ind. Crop. Prod. 2010, 31, 13-19. [CrossRef]

23. Obermeier, W.A.; Lehnert, L.W.; Pohl, M.J.; Makowski Gianonni, S.; Silva, B.; Seibert, R.; Laser, H.; Moser, G.; Müller, C.; Luterbacher, J.; et al. Grassland ecosystem services in a changing environment: The potential of hyperspectral monitoring. Remote Sens. Environ. 2019, 232, 111273. [CrossRef]

24. Ren, G.; Zhang, J.; Ma, Y. Spectral discrimination and separable feature lookup table of typical vegetation species in Yellow River Delta wetland. Mar. Environ. Sci. 2015, 34, 420-426.

25. Wu, T.; Zhao, D.; Kang, J.; Suo, A.; Wei, B.; Ma, Y. Research on remote sensing inversion biomass method based on the Suaeda Salsa's measured spectrum. Spectrosc. Spect. Anal. 2010, 30, 1336-1341. [CrossRef]

26. Zhu, L.; Chen, Z.; Wang, J.; Ding, J.; Yu, Y.; Li, J.; Xiao, N.; Jiang, L.; Zheng, Y.; Rimmington, G.M. Monitoring plant response to phenanthrene using the red edge of canopy hyperspectral reflectance. Mar. Pollut. Bull. 2014, 86, 332-341. [CrossRef]

27. González-Piqueras, J.; Lopez-Corcoles, H.; Sánchez, S.; Villodre, J.; Bodas, V.; Campos, I.; Osann, A.; Calera, A. Monitoring crop N status by using red edge-based indices. Adv. Anim. Biosci. 2017, 8, 338-342. [CrossRef]

28. Kanke, Y.; Tubaña, B.; Dalen, M.; Harrell, D. Evaluation of red and red-edge reflectance-based vegetation indices for rice biomass and grain yield prediction models in paddy fields. Precis. Agric. 2016, 17, 507-530. [CrossRef]

29. Ali, A.; Imran, M.M. Evaluating the potential of red edge position (REP) of hyperspectral remote sensing data for real time estimation of LAI \& chlorophyll content of kinnow mandarin (Citrus reticulata) fruit orchards. Sci. Hortic. 2020, 267, 109326. [CrossRef]

30. Li, L.; Ren, T.; Ma, Y.; Wei, Q.; Wang, S.; Li, X.; Cong, R.; Liu, S.; Lu, J. Evaluating chlorophyll density in winter oilseed rape (Brassica napus L.) using canopy hyperspectral red-edge parameters. Comput. Electron. Agric. 2016, 126, 21-31. [CrossRef]

31. Filella, I.; Penuelas, J. The red edge position and shape as indicators of plant chlorophyll content, biomass and hydric status. Int. J. Remote Sens. 1994, 15, 1459-1470. [CrossRef] 
32. Yao, F.; Zhang, Z.; Yang, R.; Sun, J.; Cui, S. Hyperspectral models for estimating vegetation chlorophyll content based on red edge parameter. Trans. Chin. Soc. Agric. Eng. 2009, 25, 123-129.

33. Xue, J.; Su, B. Significant Remote Sensing Vegetation Indices: A Review of Developments and Applications. J. Sens. 2017, 2017, 1-17. [CrossRef]

34. Kross, A.; McNairn, H.; Lapen, D.; Sunohara, M.; Champagne, C. Assessment of RapidEye vegetation indices for estimation of leaf area index and biomass in corn and soybean crops. Int. J. Appl. Earth Obs. 2015, 34, 235-248. [CrossRef]

35. Lu, X.; Wang, X.; Sun, H.; Yu, Y.; Wang, Y.; Yang, J.; Zhang, L. The estimation model of biomass of Suaeda Salsa in coastal wetland based on hyperspectral reflectance spectra. Trans. Oceanol. Limnol. 2017, 2, 96-100.

36. Zhao, X.; Ling, Y.; Zhang, G.; Jie, S.; Hua, W.; Ding, Y. Community characteristics of beach wetland vegetations along a habitat gradient in Dafeng Milu Reserve of Jiangsu Province. Chin. J. Ecol. 2010, 29, 244-249.

37. Zhao, S.; Shi, G.; Dong, X. The Guidance of Plant Physiology Experiments; Agricultural Science and Technology Press: Beijing, China, 2002.

38. Jiang, C.; Chen, Y.; Wu, H.; Li, W.; Zhou, H.; Bo, Y.; Shao, H.; Song, S.; Puttonen, E.; Hyyppä, J. Study of a High Spectral Resolution Hyperspectral LiDAR in Vegetation Red Edge Parameters Extraction. Remote Sens. 2019, 11, 2007. [CrossRef]

39. Ju, C.; Tian, Y.; Yao, X.; Cao, W.; Zhu, Y.; Hannaway, D. Estimating Leaf Chlorophyll Content Using Red Edge Parameters. Pedosphere 2010, 20, 633-644. [CrossRef]

40. Zhao, D.; Huang, L.; Li, J.; Qi, J. A comparative analysis of broadband and narrowband derived vegetation indices in predicting LAI and CCD of a cotton canopy. ISPRS J. Photogramm. 2007, 62, 25-33. [CrossRef]

41. Broge, N.H.; Leblanc, E. Comparing prediction power and stability of broadband and hyperspectral vegetation indices for estimation of green leaf area index and canopy chlorophyll density. Remote Sens. Environ. 2001, 76, 156-172. [CrossRef]

42. Inoue, Y.; Guérif, M.; Baret, F.; Skidmore, A.; Gitelson, A.; Schlerf, M.; Darvishzadeh, R.; Olioso, A. Simple and robust methods for remote sensing of canopy chlorophyll content: A comparative analysis of hyperspectral data for different types of vegetation. Plant Cell Environ. 2016, 39, 2609-2623. [CrossRef] [PubMed]

43. Carter, G.A. Responses of leaf spectral reflectance to plant stress. Am. J. Bot. 1993, 80, 239-243. [CrossRef]

44. Kefu, Z.; Hai, F.; San, Z.; Jie, S. Study on the salt and drought tolerance of Suaeda salsa and Kalanchoe claigremontiana under iso-osmotic salt and water stress. Plant Sci. 2003, 165, 837-844. [CrossRef]

45. Jennings, D.H. Halophytes, Succulence and Sodium in Plants-A Unified Theory. New Phytologist. 1968, 67, 899-911. [CrossRef]

46. Eshel, A. Response of Suaeda aegyptiaca to $\mathrm{KCl}, \mathrm{NaCl}$ and $\mathrm{Na}_{2} \mathrm{SO}_{4}$ treatments. Physiol. Plantarum. 1985, 64, 308-315. [CrossRef]

47. Ajmal Khan, M.; Ungar, I.A.; Showalter, A.M. The effect of salinity on the growth, water status, and ion content of a leaf succulent perennial halophyte, Suaeda fruticosa (L.) Forssk. J. Arid Environ. 2000, 45, 73-84. [CrossRef]

48. Jia, J.; Huang, C.; Bai, J.; Zhang, G.; Zhao, Q.; Wen, X. Effects of drought and salt stresses on growth characteristics of euhalophyte Suaeda salsa in coastal wetlands. Phys. Chem. Earth Parts A B C 2018, 103, 68-74. [CrossRef]

49. Song, J.; Shi, G.; Gao, B.; Fan, H.; Wang, B. Waterlogging and salinity effects on two Suaeda salsa populations. Physiol. Plantarum. 2011, 141, 343-351. [CrossRef]

50. Lu, Q.; Lu, C.; Qiu, N.; Wang, B.; Kuang, T. Does salt stress lead to increased susceptibility of photosystem II to photoinhibition and changes in photosynthetic pigment composition in halophyte Suaeda salsa grown outdoors? Plant Sci. 2002, 163, 1063-1068. [CrossRef]

51. Wang, B.; Han, J.; Zhou, Z.; Dong, Y.; Guan, X.; Jiang, B. Ecological thresholds of Suadea heteroptera under gradients of soil salinity and moisture in Daling River estuarine wetland. Chin. J. Ecol. 2014, 33, 71-75. [CrossRef]

52. Li, Y.; Chen, Z.; Wang, J.; Xu, S.; Hou, W. Effects of salt stress on Suaeda heteroptera Kitagawa growth and osmosis-regulating substance concentration. Chin. J. Ecol. 2011, 30, 72-76.

53. Qi, C.; Chen, M.; Song, J.; Wang, B. Increase in aquaporin activity is involved in leaf succulence of the euhalophyte Suaeda salsa, under salinity. Plant Sci. 2009, 176, 200-205. [CrossRef]

54. Cai Hong, P.; Su Jun, Z.; Zhi Zhong, G.; Bao Shan, W. NaCl treatment markedly enhances $\mathrm{H}_{2} \mathrm{O}_{2}$-Scavenging system in leaves of halophyte Suaeda salsa. Physiol. Plantarum 2005, 125, 490-499. [CrossRef] 
55. Liu, X.; Duan, D.; Li, W.; Tadano, T. A Comparative Study on Responses of Growth and Solute Composition in Halophytes Suaeda Salsa and Limonium Bicolor to Salinity; Springer: Dordrecht, The Netherlands, 2008; Volume 40, pp. 135-143.

56. Gitelson, A.A.; Merzlyak, M.N. Non-destructive assessment of chlorophyll carotenoid and anthocyanin content in higher plant leaves: Principles and algorithms. Remote Sens. Agric. Environ. 2004, 263, 78-94.

57. Lobos, G.A.; Retamales, J.B.; Hancock, J.F.; Flore, J.A.; Cobo, N.; Del Pozo, A. Spectral irradiance, gas exchange characteristics and leaf traits of Vaccinium corymbosum L. 'Elliott' grown under photo-selective nets. Environ. Exp. Bot. 2012, 75, 142-149. [CrossRef]

58. Garriga, M.; Retamales, J.B.; Romero-Bravo, S.; Caligari, P.D.; Lobos, G.A. Chlorophyll, anthocyanin, and gas exchange changes assessed by spectroradiometry in Fragaria chiloensis under salt stress. J. Integr. Plant Biol. 2014, 56, 505-515. [CrossRef]

59. Hernández, J.A.; Olmos, E.; Corpas, F.J.; Sevilla, F.; Del Río, L.A. Salt-induced oxidative stress in chloroplasts of pea plants. Plant Sci. 1995, 105, 151-167. [CrossRef]

60. Asada, K. The water-water cycle in chloroplasts: Scavenging of active oxygens and dissipation of excess photons. Annu. Rev. Plant Physiol. Plant Mol. Biol. 1999, 50, 601-639. [CrossRef]

61. Liu, L.; Wang, J.; Huang, W.; Zhao, C.; Zhang, B.; Tong, Q. Estimating winter wheat plant water content using red edge parameters. Int. J. Remote Sens. 2004, 25, 3331-3342. [CrossRef]

62. Zheng, J.; Li, F.; Du, X. Using Red Edge Position Shift to Monitor Grassland Grazing Intensity in Inner Mongolia. J. Indian Soc. Remote 2018, 46, 81-88. [CrossRef]

63. Fitzgerald, G.; Rodriguez, D.; O'Leary, G. Measuring and predicting canopy nitrogen nutrition in wheat using a spectral index-The canopy chlorophyll content index (CCCI). Field Crop. Res. 2010, 116, 318-324. [CrossRef]

64. Zhang, T.; Zeng, S.; Gao, Y.; Ouyang, Z.; Li, B.; Fang, C.; Zhao, B. Using hyperspectral vegetation indices as a proxy to monitor soil salinity. Ecol. Indic. 2011, 11, 1552-1562. [CrossRef]

65. Ji, C.; Zhang, Y.; Cheng, Q.; Li, Y.; Jiang, T.; San Liang, X. Analyzing the variation of the precipitation of coastal areas of eastern China and its association with sea surface temperature (SST) of other seas. Atmos. Res. 2019, 219, 114-122. [CrossRef]

66. Zhang, Y.; Huang, Z.; Fu, D.; Tsou, J.Y.; Jiang, T.; Liang, X.S.; Lu, X. Monitoring of chlorophyll-a and sea surface silicate concentrations in the south part of Cheju island in the East China sea using MODIS data. Int. J. Appl. Earth Obs. 2018, 67, 173-178. [CrossRef]

67. Ji, C.; Zhang, Y.; Cheng, Q.; Tsou, J.; Jiang, T.; Liang, X.S. Evaluating the impact of sea surface temperature (SST) on spatial distribution of chlorophyll-a concentration in the East China Sea. Int. J. Appl. Earth Obs. 2018, 68, 252-261. [CrossRef]

68. Souza, A.A.; Galvão, L.S.; Santos, J.R. Relationships between Hyperion-derived vegetation indices, biophysical parameters, and elevation data in a Brazilian savannah environment. Remote Sens. Lett. 2010, 1, 55-64. [CrossRef]

69. Peng, Y.; Gitelson, A.A. Application of chlorophyll-related vegetation indices for remote estimation of maize productivity. Agric. For. Meteorol. 2011, 151, 1267-1276. [CrossRef]

70. Kooistra, L.; Clevers, J.G.P.W. Estimating potato leaf chlorophyll content using ratio vegetation indices. Remote Sens. Lett. 2016, 7, 611-620. [CrossRef]

(C) 2020 by the authors. Licensee MDPI, Basel, Switzerland. This article is an open access article distributed under the terms and conditions of the Creative Commons Attribution (CC BY) license (http://creativecommons.org/licenses/by/4.0/). 